\title{
THE EVOLUTION OF REGIONAL
} ECONOMIC INIERLINKAGES

\section{INEUROPE}

Maria Dolores Gadea-Rivas.

Ana Gónez l oscos and Danilo Leiva- zeon

Documentos de Trabajo

N. 1705

\section{BANCODE ESPAÑA}

\author{
Eurosistema
}

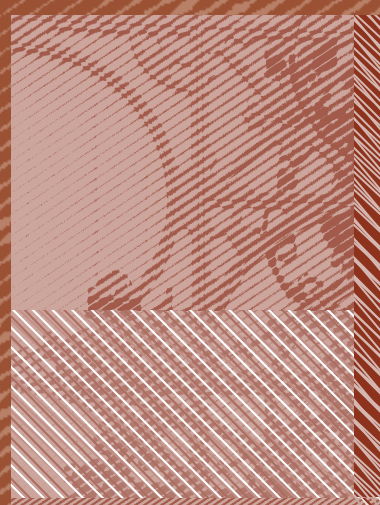


THE EVOLUTION OF REGIONAL ECONOMIC INTERLINKAGES IN EUROPE 
THE EVOLUTION OF REGIONAL ECONOMIC INTERLINKAGES IN EUROPE $\left.{ }^{*}\right)$

\author{
María Dolores Gadea-Rivas ${ }^{(*)}$
}

UNIVERSIDAD DE ZARAGOZA

Ana Gómez-Loscos ${ }^{(* *)}$

BANCO DE ESPAÑA

Danilo Leiva-Leon ${ }^{(* * *)}$

BANCO CENTRAL DE CHILE 
The Working Paper Series seeks to disseminate original research in economics and finance. All papers have been anonymously refereed. By publishing these papers, the Banco de España aims to contribute to economic analysis and, in particular, to knowledge of the Spanish economy and its international environment.

The opinions and analyses in the Working Paper Series are the responsibility of the authors and, therefore, do not necessarily coincide with those of the Banco de España or the Eurosystem.

The Banco de España disseminates its main reports and most of its publications via the Internet at the following website: http://www.bde.es.

Reproduction for educational and non-commercial purposes is permitted provided that the source is acknowledged.

(c) BANCO DE ESPAÑA, Madrid, 2017

ISSN: 1579-8666 (on line) 


\section{Abstract}

This paper studies the dynamics of the propagation of regional business cycle shocks in Europe and uncovers new features of its underlying mechanisms. To address the lack of high frequency data at the regional level, we propose a new method to measure timevarying synchronization in small samples that combines regime-switching models and dynamic model averaging. The results indicate that: (i) in just two years, the Great Recession synchronized Europe twice as much as the European Union integration process did over several decades; (ii) Ile de France is the region acting as the main channel for the transmission of business cycle shocks in Europe; followed by Inner London and Lombardia; and (iii) we identify a nonlinear relationship between sectoral composition and regional synchronization, which was amplified in the wake of the Great Recession. Similarities in services sectors are primarily responsible for this nonlinear relationship.

Keywords: business cycle, sectoral composition, regime-switching, model averaging.

JEL classification: C31, C32, E32, R11. 


\section{Resumen}

En este trabajo se analiza la dinámica de propagación de las perturbaciones de los ciclos económicos regionales en Europa y se identifican sus principales factores subyacentes. Asimismo, se propone un nuevo método para medir la sincronización variable en el tiempo en muestras pequeñas, que combina modelos de cambio de régimen y modelos de promediado dinámico (DMA, por sus siglas en inglés), y permite superar la falta de datos de alta frecuencia a nivel regional. Los principales resultados son los siguientes: i) en los dos años de la Gran Recesión la sincronización europea aumentó mucho más que durante el proceso de integración hacia la Unión Europea, que se extendió a lo largo de varias décadas; ii) Ile de France es la región que actúa como principal canal de transmisión de las perturbaciones del ciclo económico en Europa, seguida de Inner London y Lombardía; y iii), se identifica una relación no lineal entre la composición sectorial y la sincronización regional, que se ha ampliado tras la Gran Recesión. Un análisis desagregado adicional muestra que las ramas de servicios son las principales responsables de este fenómeno.

Palabras clave: ciclo económico, composición sectorial, regime-switching, model averaging.

Códigos JEL: C31, C32, E32, R11. 


\section{Introduction}

The regional dimension has been an important concern for European institutions since the establishment of the European community. Since the Treaty of Rome in 1957, there has been an increasing interest in using regional policies to reduce differences among European regions. The regional policy of the European Union (EU), known as the Cohesion Policy, makes up around one third of the total EU budget and, for decades, has been focused on diminishing regional disparities across regions. It aims to increase regional competitiveness and foster economic growth and employment at a regional level. ${ }^{1}$

In spite of the importance of the analysis of regional business cycles and their comovement, the attention given to this issue has been scarce. In contrast, numerous studies have examined the business cycle and the degree of synchronization among countries within the European Monetary Union and among European countries in general, see Camacho et al. (2006), Giannone et al. (2010) and De Haan et al. (2008) for a survey. It has to be borne in mind that country analysis can not account for within-country heterogeneity (e.g. Gadea et al. (2011)). Regional level analysis of business cycles is important because of its implications for policymakers in the design of convergence policies at the European level and in the design of fiscal policies to reduce regional disparities at the country level.

Most of the studies that have focused on describing overall regional cyclical patterns can be divided into two strands. The first focuses on analyzing regional convergence (Ramajo et al. (2008), Quah (1996) and Sala-i-Martin (1996)) and on identifying the determinants of long-term economic performance at the regional level (Ozyurt and Dees (2015) and Rodriguez-Pose (2013)). The second, which is directly related to our work, focuses on the synchronization of short-term fluctuations in regional real activity. These studies usually compute pairwise correlations of different measures of the regional cycles with respect to country-specific cycles, to identify 'border effects', or to a reference cycle, such as the European one. ${ }^{2}$ The measure of regional economic activity has also varied across studies. Fatas (1997), Barrios and De Lucio (2003) and Belke and Heine (2006) use employment data, while Acedo-Montoya and de Haan (2008) and Barrios et al. (2003) use gross value added and Clark and van Wincoop (2001) employ both measures of real economic activity to compare synchronization patterns among European countries and US Census regions. ${ }^{3}$ Marino (2013) uses a different methodological approach that is based on dynamic factor models to analyze regional fluctuations of GDP and employment.

\footnotetext{
${ }^{1}$ http://ec.europa.eu/regional_policy/en/policy/what/investment-policy/

${ }^{2}$ For the US, Hamilton and Owyang (2012) study similarities and differences across US states finding clusters of states sharing certain business cycle characteristics.

${ }^{3}$ For a summary review of this literature, see Acedo-Montoya and de Haan (2008).
} 
It is worth noting that Europe has not only experienced significant policy changes to strengthen its unification process, but has also been exposed to large contractionary business cycle shocks, coming from the foreign side, during the Great Recession, and from the domestic side, during the recent 'Debt Crisis'. These factors may have produced significant changes in the overall patterns of regional business cycle synchronization. Although the studies mentioned above provide a better understanding of business cycle comovements at the regional level, they are not able to endogenously identify changes in the patterns of regional synchronization. This is an important limitation in evaluating the effect of policy and aggregate shocks over time.

In this paper, we study the dynamics of the propagation of regional business cycle shocks in Europe and uncover new features of its underlying mechanisms, in particular, those related to the role that sectoral composition plays in explaining these dynamics. Our work has some advantages over the previous literature and provides a threefold contribution. First, we use data with a broader coverage in the time and space dimensions than previous studies. Our study, which covers the last three global recessions (1982, 1991 and 2009), ${ }^{4}$ is the first to capture the effects of the Great Recession and the European debt crisis on regional synchronization. Hence, we can compare their effects to those of important milestones in Europe, including the Maastricht Treaty and the introduction of the euro. Furthermore, we analyze a wider and more disaggregated geographical coverage, considering a range of 213 European regions based on the NUTS2 classification (Nomenclature of territorial units for statistics, at the second level) and corresponding to 16 European countries for a period of 35 years (1980-2014) with a yearly frequency. ${ }^{5}$ Most of the previous studies look at a smaller number of European regions (NUTS1 level) and a shorter period of time. ${ }^{6}$ Finally, we employ the most comprehensive measure of real economic activity, that is, real GDP data as the literature on national business cycle synchronization usually does.

Second, we propose a methodology to measure time-varying synchronization in small samples that allows us to overcome the short length of the series produced by the lack of high frequency data. In doing so, we combine the regime-switching synchronization approach, proposed in Leiva-Leon (2016), with the dynamic model averaging framework for Markov-switching models, proposed in Guérin and Leiva-Leon (2015), to produce a flexible framework that allows us to estimate business cycle time-varying synchronization. Monte

\footnotetext{
${ }^{4}$ See IMF (2009), for a definition of global recessions.

${ }^{5}$ The NUTS 2013 classification lists 98 regions at NUTS1 level, 276 regions at NUTS2 level and 1,342 regions at NUTS 3 level. The regions eligible for the support of Cohesion policy are defined at NUTS 2 level.

${ }^{6}$ Barrios and De Lucio Fernandez (2003) include 20 Spanish and Portuguese regions for 1988-1998; Belke and Heine (2006) work with 30 regions from 6 countries for 1989-1996; Fatas (1997) uses 38 regions from 4 countries for 1966-1992; Acedo-Montoya and de Haan (2008) consider 53 regions from 12 countries for 1975-2005; and Marino (2013) employs 107 regions (30 NUTS1 and 77 NUTS2 regions) from 9 countries for $1977-1995$
} 
Carlo simulations validate the reliability of the proposed framework when dealing with scarce information in the time dimension. An alternative rolling approach is not suitable in this case because of the short number of observations (35 data points). Our approach not only deals with this limitation, but also provides measures of uncertainty for the estimated dynamic synchronizations. It should be noted that most of the papers that analyze synchronization among European regions use standard measures of pairwise correlation, only differing in some cases in the measure of the cycle (percentage changes or different filters, such as the Hodrick-Prescott filter).

Third, our framework is able to endogenously identify changes in regional synchronization patterns over time and to provide assessments about the main factors associated to those changes. The information contained in the bilateral business cycle linkages allows us to identify the regions that play the most important role in the propagation of business cycle shocks in Europe. Moreover, since it has been documented in the literature that sectoral composition represents a key factor in explaining business cycle synchronization, we analyze it in greater depth. ${ }^{7}$ In particular, we focus on assessing potential instabilities and nonlinearities in the relationship between sectoral composition similarities and business cycle similarities across European regions. To provide robust assessments of our results, we employ both parametric and non-parametric econometric approaches.

The main findings of our analysis are the following. First, most of the European core countries have experienced an increasing internal synchronization over time, while the Nordic countries and the British Isles show a rather different pattern, with a general decline in internal synchronization since the introduction of the euro. ${ }^{8}$ Second, in only two years the Great Recession lead to a significant increase in the level of regional synchronization about twice as large as the one associated to the European Union integration process until then. After the Great Recession, the level of regional synchronization experienced a decline, but it remained at significantly higher levels than before this event. Third, Ile de France is the region that acts as the main conduit in the propagation of business cycle shocks throughout Europe, followed by Inner London and Lombardia. During the 1980s and 1990s, Ile de France was strongly connected to Inner London and to some regions of West Germany and North Italy. The introduction of the euro led to a higher connectivity between some Spanish regions and the other European regions. During the Great Recession, the European regional business cycle network experienced the strongest degree of connectedness, which remained relatively high several years after it. Fourth, we document a gradual but persistent increase in the

\footnotetext{
${ }^{7}$ Imbs (2004) and Ductor and Leiva-Leon (2016) show that similarities in sectoral composition plays an important role in determining international business cycle synchronization.

8 "Internal synchronization" refers to the synchronization that all the regions that belong to a specific country exhibit.
} 
similarities of regional sectoral composition over time. This result has important implications for the propagation of shocks throughout the European economy because the more similar the economic structure among regions, the more similar would be their responsiveness to shocks, potentially amplifying their effects at the aggregate level. Fifth, we find that the similarities of regional sectoral composition have become significantly more important in explaining regional synchronization in Europe since the Great Recession. Moreover, the results document a nonlinear relationship between sectoral composition and regional business cycle synchronization, which is mainly due to sectors related to services.

The remainder of the paper is organized as follows. Section 2 presents the methodology for measuring time-varying synchronization and assesses its reliability with simulated data. Section 3 describes the dataset and analyzes regional business cycle synchronization patterns across time and space dimensions. Section 4 investigates the relationship between the regional synchronization and similarities in sectoral composition. Finally, Section 5 concludes.

\section{Measuring regional business cycle synchronization}

Regime-switching models have been widely used to infer endogenous changes over time in the synchronization of business cycle phases, at the country level (Ductor and Leiva-Leon (2016)), and at the regional (Leiva-Leon (2016)) and sectoral level (Camacho and LeivaLeon (2016)) for the US. However, the econometric framework used in these studies requires a set of information associated with relatively large time spans in order to provide inferences on changes of synchronization regimes (e.g. high or low). This is an important limitation to analyze endogenous changes in the synchronization of European regional business cycles because regional real GDP data is available yearly from 1980 to 2014, leaving only 35 observations in the time dimension of our analysis. Alternative rolling approaches are not suitable for analyzing endogenous changes in synchronization in the present case because of there are few observations. In this section, we propose a framework that allows us to overcome the limitations of the short sample and provide an estimation of the changes in synchronization.

\subsection{The model}

To measure business cycle synchronization, we follow the line proposed in Harding and Pagan (2006) who focus on testing the hypothesis that cycles are either unsynchronized or perfectly synchronized during a given sample period. In this section, we propose an econometric framework to assess the degree of business cycle synchronization over time using Dynamic Model Averaging to account for both polar cases of synchronization. Let $Y_{a, t}$ and $Y_{b, t}$ be the real GDP of European regions " $a$ " and " $b$ ", respectively. To focus on cyclical fluctuations, 
we define $y_{k, t}=100 \times \Delta \log \left(Y_{k, t}\right)$ as the real GDP growth of region " $k$ ", and model their joint dynamics following Leiva-Leon (2016), that is

$$
\left[\begin{array}{l}
y_{a, t} \\
y_{b, t}
\end{array}\right]=\left[\begin{array}{l}
\mu_{a}\left(S_{a, t}\right) \\
\mu_{b}\left(S_{b, t}\right)
\end{array}\right]+\left[\begin{array}{l}
e_{a, t} \\
e_{b, t}
\end{array}\right], \quad\left[\begin{array}{l}
e_{a, t} \\
e_{b, t}
\end{array}\right] \sim N(0, \Sigma)
$$

where

$$
\mu_{k}\left(S_{k, t}\right)=\mu_{k, 0}+\mu_{k, 1} S_{k, t}, \quad \text { for } k=a, b,
$$

and $S_{k, t}$ denotes a latent state variable that indicates the state of the economy of region $k$. It takes the value $S_{k, t}=0$ if region $k$ is in a low growth regime, which can be interpreted as a recessionary phase, or the value of $S_{k, t}=1$ if region $k$ is in a high growth regime, which can be interpreted as an expansionary phase. Each state variable is assumed to follow a first-order Markov process with transition probabilities given by

$$
p\left(S_{k, t}=j_{k} \mid S_{k, t-1}=i_{k}, S_{k, t-2}=h_{k}, \ldots\right)=p\left(S_{k, t}=j_{k} \mid S_{k, t-1}=i_{k}\right)
$$

and the variance covariance matrix $\Sigma$ is assumed to be non-diagonal.

The dependency relationship between the state variables provides information about the synchronization of the economic cycles of the two regions. Despite the complexity involved in modelling the exact dependency relationship between $S_{a, t}$ and $S_{b, t}$, we are able to model their joint dynamics, summarized in the state variable $S_{a b, t}$, under the two extreme cases. ${ }^{9}$ The first corresponds to the independent case, where the joint probability is the product of the marginal probabilities,

$$
p\left(S_{a b, t}^{I}=i_{a b}\right)=p\left(S_{a, t}=i_{a}\right) p\left(S_{b, t}=i_{b}\right)
$$

The second corresponds to the fully dependent case, where $S_{a, t}=S_{b, t},=S_{t}$, and the joint probability is modelled as

$$
p\left(S_{a b, t}^{D}=i_{a b}\right)=p\left(S_{t}=i\right)
$$

where $S_{t}$ is a state variable that governs the whole dynamics of the system in Equation (1) and has its own transition probabilities

$$
p\left(S_{t}=j \mid S_{t-1}=i, S_{t-2}=h, \ldots\right)=p\left(S_{t}=j \mid S_{t-1}=i\right) .
$$

\footnotetext{
${ }^{9}$ Phillips (1991) and Bengoechea et al. (2006) model the synchronization between two economies as a combination of two extreme situations: independent and fully dependent.
} 
Our goal is to provide assessments about the degree of business cycle synchronization between regions " $a$ " and " $b$ ", which can be interpreted as a linear combination between the two extreme cases. Moreover, we are interested in providing information about the degree of synchronization for each period of time. Therefore, we model the joint probability of state variables as follows

$$
p\left(S_{a b, t}=i_{a b}\right)=p\left(S_{a b, t}^{D}=i_{a b}\right) \delta_{t}^{a b}+p\left(S_{a b, t}^{I}=i_{a b}\right)\left(1-\delta_{t}^{a b}\right)
$$

where the weight $\delta_{t}$ can be interpreted as the degree of synchronization between the two regions at time $t$. To model $\delta_{t}$, Leiva-Leon (2016) introduces another state variable that indicates either regimes where the independent case, $p\left(S_{a b, t}^{I}=i_{a b}\right)$, provides a better characterization of the model's dynamics or regimes where the dependent case, $p\left(S_{a b, t}^{D}=i_{a b}\right)$, is the most appropriate characterization. However, inferences about the time-varying synchronization using this framework are less accurate when the number of observations contained in $y_{t}$ is very limited. This is because synchronicity regimes (independent or fully dependent) are considered to be a sequence of several time periods where the latent variables follow specific dynamics. Due to the data limitations at regional level, our available information consists of only 34 data points in the time dimension (after computing growth rates).

To overcome this drawback, in this paper, we propose a flexible way to compute $\delta_{t}^{a b}$, which is not based on the assumption of regimes of dependency. Instead, we use Dynamic Model Averaging to infer time periods where one polar case, the independent or fully dependent, provides the best characterization of the data in $y_{t}$. This procedure allows us to capture changes in European regional synchronization with the 34 observations available at a yearly frequency.

\subsection{Dynamic model averaging}

Dynamic model averaging (DMA) was initially proposed by Raftery et al. (2010) and motivated by taking into account time variation in model uncertainty. DMA has been applied in the context of time-varying parameter (TVP) regression models (Koop and Korobilis (2012)), linear vector autoregressive (VAR) models (Koop (2014)) and large TVP-VAR models (Koop and Korobilis (2013)) to forecast inflation, real output and interest rates. Recently, Guérin and Leiva-Leon (2015) proposed an algorithm to use DMA in the context of Markov-switching (MS) models and use it to predict recessions under model uncertainty. Accordingly, we can think of the real GDP growth of regions " $a$ " and " $b$ ", $\left(y_{a, t}, y_{b, t}\right)^{\prime}$, being modelled either under the assumption of two independent business cycles driving each econ- 
omy, $p\left(S_{a b, t}^{I}=i_{a b}\right)$ or under the assumption of only one common business cycle driving both economies, $p\left(S_{a b, t}^{D}=i_{a b}\right)$. In this context, the time-varying weight, $\delta_{t}^{a b}$, allows us to deal with model uncertainty and to assess which specification provides a better fit of the data for each period of time. Therefore, we can interpret our synchronization framework in Equation (7) as a dynamic average of two MS models and follow the line of Guérin and Leiva-Leon (2015) to compute $\delta_{t}^{a b}$.

Taking the model's parameters as known and suppressing the indexes " $a$ " and " $b$ " for ease of notation, the algorithm used to obtain the elements in equation (7) consists of iteratively computing the following steps.

Step 1: predicting regime probability. Using the corresponding transition probabilities for the independent model, $p^{I}=p\left(S_{a, t} \mid S_{a, t-1}\right) \times p\left(S_{b, t} \mid S_{b, t-1}\right)$, and for the fully dependent model, $p^{D}=p\left(S_{t} \mid S_{t-1}\right)$, as defined in equations (3) and (6), respectively, compute the predicted regime probabilities, $p\left(S_{t}^{m} \mid, \psi_{t-1}\right)$, for $m=I, D$, given past information $\psi_{t-1}$, being $j=[0,1]$ and $i=[0,1] .^{10}$

$$
\begin{gathered}
p\left(S_{t}^{m}=j, S_{t-1}^{m}=i \mid \psi_{t-1}\right)=p^{m} p_{i j}\left(S_{t-1}^{m}=1 \mid \psi_{t-1}\right) \\
p\left(S_{t}^{m}=j \mid \psi_{t-1}\right)=\sum_{S_{t-1}^{m}} p\left(S_{t}^{m}=j, S_{t-1}^{m}=i \mid \psi_{t-1}\right)
\end{gathered}
$$

Then, the predictive likelihood is calculated from the predicted regime probabilities:

$$
f_{m}\left(y_{t} \mid \psi_{t-1}\right)=\sum_{S_{t}^{m}} \sum_{S_{t-1}^{m}} f_{m}\left(y_{t} \mid S_{t}^{m}=j, S_{t-1}^{m}=i, \psi_{t-1}\right) p\left(S_{t}^{m}=j, S_{t-1}^{m}=i \mid \psi_{t-1}\right) .
$$

Step 2: updating model probability. Let $M_{t} \in\{I, D\}$ be a variable that indicates the model that applies at each period of time. Also, to simplify notation, let $\pi_{t \mid t-1, m}=$ $p\left(M_{t}=m \mid \psi_{t-1}\right)$ be the predictive probability associated with the $m$-th MS model at time $t$, given the information up to $t-1$. Starting with an equal-weight initial-model probability $p\left(M_{0}\right)$, we follow the updating criterion of Raftery et al. (2010), which is based on a measure of model fit for $y_{t}$, that is, the predictive likelihood:

$$
\pi_{t \mid t, m}=\frac{\pi_{t \mid t-1, m} f_{m}\left(y_{t} \mid \psi_{t-1}\right)}{\sum_{r=1}^{2} \pi_{t \mid t-1, r} f_{r}\left(y_{t} \mid \psi_{t-1}\right)} .
$$

\footnotetext{
${ }^{10}$ The Hamilton filter is initialized with the ergodic probabilities $P\left(S_{0}\right)$.
} 
Step 3: updating regime probability. Use the predictive likelihood, $f_{m}\left(y_{t} \mid \psi_{t-1}\right)$, to compute the updated regime probabilities, $p\left(S_{t}^{m} \mid \psi_{t}\right)$, for both models, as follows:

$$
\begin{aligned}
p\left(S_{t}^{m}=j, S_{t-1}^{m}=i \mid \psi_{t}\right) & =\frac{f_{m}\left(y_{t}, S_{t}^{m}=j, S_{t-1}^{m}=i \mid \psi_{t-1}\right)}{f_{m}\left(y_{t} \mid \psi_{t-1}\right)} \\
& =\frac{f_{m}\left(y_{t} \mid S_{t}^{m}=j, S_{t-1}^{m}=i, \psi_{t-1}\right) p\left(S_{t}^{m}=j, S_{t-1}^{m}=i \mid \psi_{t-1}\right)}{f_{m}\left(y_{t} \mid \psi_{t-1}\right)} \\
& p\left(S_{t}^{m} \mid \psi_{t}\right)=\sum_{S_{t-1}^{m}} p\left(S_{t}^{m}=j, S_{t-1}^{m}=i \mid \psi_{t}\right)
\end{aligned}
$$

These are used in Step 1 of the next iteration.

Step 4: predicting model probability. Compute the predicted probability associated with the $m$-th model, $\pi_{t+1 \mid t, m}$, following Raftery et al. (2010) and using the forgetting factor $\alpha$, as follows:

$$
\pi_{t+1 \mid t, m}=\frac{\pi_{t \mid t, m}^{\alpha}}{\sum_{r=1}^{2} \pi_{t \mid t, r}^{\alpha}}
$$

This is used in Step 2 of the next iteration. The forgetting factor $\alpha$ is the coefficient that governs the amount of persistence in the models' weights, the higher the $\alpha$, the greater the weight attached to past predictive performance. It is commonly set to a fixed value slightly less than one. However, in our context, due to the small sample size, small variations in $\alpha$ may influence the dynamics of $\pi_{t+1 \mid t, m}$. Therefore, instead of simply imposing a given forgetting factor, we estimate it along with the other parameters of the model using Bayesian methods.

We repeat the steps above for $t=1, \ldots, T$. The output of the algorithm consists of the regime probabilities for each model, $p\left(S_{t}^{m} \mid \psi_{t}\right)$, for $m=I, D$, and the model probabilities for each time period, $\pi_{t \mid t, m}$. Therefore, we compute the expected joint regime probabilities by averaging across models:

$$
p\left(S_{a b, t}=i_{a b} \mid \psi_{t}\right)=p\left(S_{t}^{D} \mid \psi_{t}\right) \pi_{t \mid t, D}+p\left(S_{t}^{I} \mid \psi_{t}\right) \pi_{t \mid t, I}
$$

where $\pi_{t \mid t, D}=\delta_{t \mid t}$, and $\pi_{t \mid t, I}=\left(1-\delta_{t \mid t}\right)$, following the notation in equation (7). Another advantage of the proposed approach is that it does not only provide a point estimate of the degree of synchronization, but is also able to compute the entire distribution of the synchronization at a given time period. From which we can obtain a measure of uncertainty associated with the estimated synchronization. 


\subsection{Estimation}

Since the likelihood function of the model in equations (1)-(7) is conditional on many possible states, the parameter estimation obtained with the maximum likelihood approach could become cumbersome. Therefore, we use a Bayesian approach to estimate this model. In particular, the approach to estimate the vector of the model's parameters, $\theta$, is based on a multivariate extended version of the multi-move Gibbs-sampling procedure developed by Kim and Nelson (1999). In this setting, (i) the parameters of the model, $\theta$, (ii) the Markovswitching variables, $\tilde{S}_{a, T}=\left\{S_{a, t}\right\}_{1}^{T}, \tilde{S}_{b, T}=\left\{S_{b, t}\right\}_{1}^{T}, \tilde{S}_{T}=\left\{S_{t}\right\}_{1}^{T}$, and (iii) the synchronization measure, $\tilde{\delta}_{T}=\left\{\delta_{t}\right\}_{1}^{T}$, are treated as random variables given the data, $\tilde{y}_{T}=\left\{y_{t}\right\}_{1}^{T}$. The purpose of this Markov chain Monte Carlo simulation method is to proxy the joint and marginal distributions of these random variables by sampling from conditional distributions.

The Gibbs sampler used in the estimation procedure can be briefly described in the following steps:

Step 1: Generate the latent variables, $\tilde{S}_{a, T}, \tilde{S}_{b, T}, \tilde{S}_{T}$, and the weights, $\tilde{\delta}_{T}$, conditional on the data, $\tilde{y}_{T}$, and the vector of parameters, $\theta$.

Step 2: Generate the transition probabilities associated with each latent variable, $p_{00, a}$, $p_{11, a}, p_{00, b}, p_{11, b}, p_{00}, p_{11}$, conditional on $\tilde{S}_{a, T}, \tilde{S}_{b, T}, \tilde{S}_{T}$, and $\tilde{\delta}_{T}$.

Step 3: Generate the means associated with each state, $\mu_{a, 0}, \mu_{a, 1}, \mu_{b, 0}, \mu_{b, 1}$, conditional on $\sigma_{a}^{2}, \sigma_{b}^{2}, \sigma_{a b}, \tilde{S}_{a, T}, \tilde{S}_{b, T}, \tilde{S}_{T}, \tilde{\delta}_{T}$ and $\tilde{y}_{T}$.

Step 4: Generate the variance-covariance matrix, with elements $\sigma_{a}^{2}, \sigma_{b}^{2}, \sigma_{a b}$, conditional on $\mu_{a, 0}, \mu_{a, 1}, \mu_{b, 0}, \mu_{b, 1}, \tilde{S}_{a, T}, \tilde{S}_{b, T}, \tilde{S}_{T}, \tilde{\delta}_{T}$ and $\tilde{y}_{T}$.

Step 5: Generate the forgetting factor, $\alpha$, conditional on $\tilde{\delta}_{T}$.

Steps 1 through 5 can be iterated $L+M$ times, where $L$ is large enough to ensure that the Gibbs sampler has converged. Thus, the marginal distributions of the state variables, the synchronization variable and the parameters of the model can be proxied by the empirical distribution of the $M$ simulated values. We set $M=6000$ and $L=1000$. For detailed information about each step of the Gibbs sampler and the prior distributions employed, see Appendix A.

\subsection{Simulations}

In this section, we conduct Monte Carlo simulations to compare the finite sample performance of the method proposed in this paper to measure time-varying synchronization and the method proposed in Leiva-Leon (2016) for the same purpose. Our goal is to examine the accuracy of the two methods in inferring changes in synchronization under different scenarios, which consider (i) the gap between the state-dependent parameters, (ii) the volatility of the series, and (iii) the size of the sample. 


\subsubsection{Design}

The experiment consists of generating two series, $y_{a, t}$ and $y_{b, t}$, governed by two latent state variables, $S_{a, t}$ and $S_{b, t}$, respectively, in accordance with the following parsimonious system,

$$
\left[\begin{array}{l}
y_{a, t} \\
y_{b, t}
\end{array}\right]=\left[\begin{array}{l}
\mu_{S_{a, t}} \\
\mu_{S_{b, t}}
\end{array}\right]+\left[\begin{array}{l}
e_{a, t} \\
e_{b, t}
\end{array}\right]
$$

where $\mu_{S_{i, t}}=\mu_{i, 0}+\mu_{i, 1} S_{i, t}$, for $i=a, b$, and the innovations $e_{t}=\left[e_{a, t}, e_{b, t}\right]^{\prime}$, are normally distributed, that is, $e_{t} \sim N(0, \Omega)$. The latent state variables are assumed to undergo changes in their synchronization over time, which are generated as follows.

First, let $\tilde{S}_{a, t}$ be a state vector of sequence $a$ at time $t$. If the sequence $a$ is in state 1 at time $t$, we write $\tilde{S}_{a, t}=(1,0)^{\prime}$, and if it is in state 2 at time $t$, we write $\tilde{S}_{a, t}=(0,1)^{\prime}$. The vector $\tilde{S}_{a, t}$ is assumed to follow a first-order Markov chain. For time $t$, compute $\left(q_{a}, 1-q_{a}\right)^{\prime}=P_{a} \tilde{S}_{a, t}$, where

$$
P_{a}=\left(\begin{array}{cc}
p_{a, 11} & 1-p_{a, 22} \\
1-p_{a, 11} & p_{a, 22}
\end{array}\right),
$$

is the transition probability matrix, and the realization of the sequence at time $t+1$ is defined as

$$
\tilde{S}_{a, t+1}=\left\{\begin{array}{c}
(1,0)^{\prime}, \quad \text { if } q_{a} \geq \theta \\
(0,1)^{\prime}, \text { otherwise }
\end{array}\right.
$$

where $\theta$ is drawn from a $U[0,1]$. Second, in an analogous way, generate an independent Markovian sequence, $\tilde{S}_{b, t}$, with its corresponding transition probability matrix, $P_{b}$. Third, generate another Markovian sequence, $\tilde{V}_{t}$, with its corresponding transition probability matrix, $P_{V}$, that governs the changes of synchronization between $\tilde{S}_{a, t}$ and $\tilde{S}_{b, t}$ according to the following rule:

$$
\begin{aligned}
& S_{a, t}=\tilde{S}_{a, t[1]}, \\
& S_{b, t}=\left\{\begin{array}{c}
\tilde{S}_{a, t[1]}, \text { If } V_{t}=(1,0)^{\prime} \\
\tilde{S}_{b, t[1]}, \text { If } V_{t}=(0,1)^{\prime}
\end{array},\right.
\end{aligned}
$$

where $\tilde{S}_{i, t[1]}$ denotes the first element of the sequence vector for $i=a, b$.

For simplicity, we assume that $p_{a, 11}=p_{b, 11}=0.9$, and $p_{a, 22}=p_{b, 22}=0.8$. Since our application involves dealing with a small sample, we are interested in generating a small number of random changes of synchronization during the time span, $T$. In doing so, we relate 
the transition probabilities of the state variable that indicates changes in synchronization, $p_{v, 11}=p_{v, 22}=p_{v}$, to the sample size, $T$, based on an expected duration of one change over the entire sample, ${ }^{11}$

$$
p_{v}=1-\frac{2}{T}
$$

We control for three dimensions in our simulations. First, we focus on the dispersion between the state-dependent means, defined as $\bar{\mu}=\left|\mu_{S_{i, t}=1}-\mu_{S_{i, t}=0}\right|$, keeping a mean between $\mu_{S_{i, t}=1}$ and $\mu_{S_{i, t}=0}$ equal to zero. We consider a set given by $\bar{\mu}=\{0.5,1,2\}$. Second, we assess the effect of the volatility associated with the innovations of the data. For simplicity, we assume that $\sigma_{11}^{2}=\sigma_{22}^{2}=\sigma_{12}^{2}=\sigma^{2}$, and study different scenarios of volatility given by the set $\sigma^{2}=\{0.5,1,2\}$. Our main interest is in the performance of the models under different sizes of the available sample. Therefore, we evaluate the finite sample properties by repeating the simulations associated with each configuration of parameters for the set of sample sizes, $\mathbf{T}=\{30,50,70,100,200,400\}$. We perform $M=1000$ simulations for each configuration of parameters, $\bar{\mu}$ and $\sigma^{2}$, and for each sample size, $T$, under consideration.

\subsubsection{Results}

At each $m$-th replication, we compute the time-varying synchronization estimated with the forgetting factor $(F F)$ method proposed in this paper and define it as $\delta_{t}^{m}$. We also compute the time-varying synchronization estimated with the Markov-chain $(M C)$ method, proposed in Leiva-Leon (2016), and define it as $d_{t}^{m}$. For each replication, we compute the Quadratic Probability Score (QPS) associated with each method, taking the variable indicating the true synchronization changes, $V_{t}=\tilde{V}_{t[1]}$, as our reference. Our object of interest is the average QPS over the $M$ replications associated with each method, calculated as,

$$
\begin{aligned}
Q P S_{\delta} & =\frac{1}{M} \sum_{m=1}^{M}\left[\frac{1}{T} \sum_{t=1}^{T}\left(V_{t}^{m}-\delta_{t}^{m}\right)^{2}\right], \\
Q P S_{d} & =\frac{1}{M} \sum_{m=1}^{M}\left[\frac{1}{T} \sum_{t=1}^{T}\left(V_{t}^{m}-d_{t}^{m}\right)^{2}\right] .
\end{aligned}
$$

Table 1 reports the simulation results based on $M=1000$ replications. The results indicate that the ability of both methods to accurately infer changes in synchronization increases as the dispersion between the state-dependent increases and the volatility of the innovations decreases. Regarding the scenarios of different sample sizes, the table shows

\footnotetext{
${ }^{11}$ We relate the expected duration of a synchronization regime (high or low), $p_{v}^{E}$, defined as $p_{v}^{E}=\frac{1}{1-p_{v}}$, to the number of time periods that the series would remain in that regime, $\tau$. Since we are interested in generating (on average) one change of synchronization, $\tau=\frac{T}{2}$.
} 
that, for small samples $(T=30)$, the $F F$ method outperforms the $M C$ method in $78 \%$ of the cases. However, when the sample increases, the relative performance of the $F F$ method with respect to the $M C$ method tends to decrease. For $T=50, T=100$, and $T=200$, the FF method outperforms the $M C$ method in $67 \%, 56 \%$, and $44 \%$, of the cases, respectively. From these exercises we conclude that the method to assess changes in synchronization proposed in this paper performs significantly better than the $M C$ method in small samples, but it also is competitive in large samples.

\section{Assessing changes in regional interdependence}

\subsection{Data}

The sample consists of 213 regions, following the NUTS-2 classification, that correspond to 16 European countries: the EU-12 (Austria (AT), Belgium (BE), Finland (FI), France (FR), Germany (DE), Ireland (IE), Italy (IT), Luxembourg (LU), Netherlands (NL), Portugal (PT), Spain (ES) and Greece (GR)) and Denmark (DK), Norway (NO), Sweden (SE) and the United Kingdom (UK). For Germany, data of the eastern Landers and Berlin are not available prior to 1991. Therefore, they are not included in our analysis.

The availability of regional data on a high frequency basis and for a long span is scarce. To analyze the synchronization of the regional business cycles, we employ the most comprehensive measure of real economic activity, that is, annual real GDP data, as quarterly data is not available. This is the most common measure in the literature on business cycle synchronization at country level while the measure of economic activity at regional level varies across studies, as previously mentioned. The series cover a period of 35 years, from 1980 to 2014. Thus, the potential effects of the Great Recession and the European Debt Crisis on the regional business cycle of the European countries are analyzed for the first time.

The source of the data is the Cambridge Econometrics database, which contains data collected from Eurostat's REGIO database and from AMECO, a dataset provided by the European Commission's Directorate General Economic and Financial Affairs (DG EcFin). ${ }^{12}$

\subsection{Bilateral economic linkages}

Much of the literature about business cycle synchronization is based on dynamic factor models to infer changes in the comovement between the real activity of different economies and some common (or global) factors. Some examples are Kose et al. (2012) and Del

\footnotetext{
${ }^{12}$ The GDP series are deflated with 2005 constant price euros using price deflators obtained from AMECO.
} 
Negro and Otrok (2008), among others, at country level and Marino (2013) at regional level. However, factor models are not able to provide information about changes in the bilateral relationship of the business cycles associated with a pair of regions, which would provide a more detailed picture about the propagation patterns of contractionary and expansionary shocks and to identify the regions acting as main conduits in the propagation process.

In order to illustrate how to interpret the output of our econometric framework, Figure 1 shows the time-varying business cycle synchronization for a couple of selected pairs of regions. Chart A illustrates the synchronization between two capital regions of relatively small countries, Brussels-Capital (BE) and Noord-Holland (NL). The chart shows an almost constant level of synchronization until the early 1990s. However, after the Maastricht Treaty, both regions started to experience a persistent increase in business cycle synchronization until the end of the sample, in 2014. Chart B depicts the pattern of synchronization between two capital regions of relatively large countries, Ile de France (FR) and Inner London (UK). The chart shows an upward trend in synchronization after the Maastricht Treaty in 1992, followed by a transient fall in 2000 due to the introduction of the euro in only one of the two economies, and a significant increase in the level of synchronization after the Great Recession, which remained quite high a few years after it.

On a related matter, the United Kingdom will leave the European Union following the June 2016 referendum vote. With the exit of the UK from the EU, an event commonly known as "Brexit", global economic and policy uncertainty has significantly increased since negative economic consequences, not only for the UK but also for the economies that remain in the EU, are expected. Considering this scenario, it is interesting to analyze the relationship between the UK and the European regions with the most recent data available. Our proposed framework can be used to shed some light on the strength of these economic interrelations. First, we aggregate the regions of the UK. Second, we estimate its time-varying business cycle interdependence with each of the remaining regions of Europe. Finally, we select the most updated set of estimated synchronization measures, corresponding to the year 2014, and use a heatmap to visualize this information. Figure 2 shows the strength of the connections between the UK and the European regions, indicating that the regions that currently exhibit the strongest connection with the UK are the regions located in Finland, Sweden, West Germany, Northern Italy, Austria and some regions in the middle of France.

\subsection{Synchronization across time and space}

To investigate the overall spectrum of the aggregate economic interlinkages between the European regions, we estimate the model in equations (1)-(7) for each pair of regions in our sample. Since our sample consists of 213 regions, there are a total of 22,578 pairwise possible 
combinations. It is important to mention that, in spite of certain common patterns, there is a significant heterogeneity associated with the idiosyncrasy of each bilateral regional relationship, which may be due to multiple factors. The aim of this section is not to investigate the characteristics behind each pairwise synchronization, but to identify the main features of their overall patterns that would help us to understand the propagation of business cycle shocks at the regional level.

We start by providing a general assessment about the regions experiencing the highest levels of synchronization with the rest of Europe. To do so, we compute the following index of "aggregate" synchronization for each region:

$$
d_{t}^{i}=\frac{1}{n} \sum_{j=1}^{n} \delta_{t}^{i j}, \text { for } i=1,2, \ldots, n,
$$

where $n=213$ regions and $d_{t}^{i}$ provides information about the overall degree of synchronization of region $i$ with the rest of Europe at time $t$. Figure 3 plots heat maps of the synchronization patterns in Europe for different time periods, measured by $d_{t}^{i}$, namely, for 1981 (the beginning of our sample), 1999 (the introduction of the euro), 2009 (the Great Recession) and 2014 (end of the sample). Chart A of Figure 3 shows that, in 1981, almost all the regions of Europe were experiencing a relatively low synchronization, ranging between 0.3 and 0.5. However, during the implementation of the euro, many regions of Spain, France, Germany and Italy, and even some regions of the United Kingdom, became more synchronized with the rest of Europe, exhibiting levels of synchronization between 0.5 and 0.7 , as can be seen in Chart B. In the middle of the Great Recession, many regions experienced high levels of synchronization, showing evidence of the propagation of a contractionary shock during this time in particular, as can be seen in Chart C. For example, most of the Spanish regions experienced synchronization levels with the rest of Europe of between 0.7 and 0.9 , this agrees with the fact that Spain was one of the European countries most affected by the Great Recession. Finally, Chart D plots the map corresponding to the end of the sample, 2014 , showing that although the overall degree of regional synchronization has suffered a certain setback after the end of the Great Recession, it has remained at relatively high levels, ranging between 0.5 and 0.7 .

The information in Figure 3 provides just a visual assessment of the effect of events such as the introduction of the euro and the Great Recession in Europe. The rest of this section focuses on quantifying the effect of these and other events across European regions more precisely.

Having estimated all the economic bilateral linkages between the European regions, $\delta_{t}^{a b}$ for all $i \neq j$, we now analyze this information from two different perspectives: temporal and geographical. First, we focus on the time dimension and "collapse" the space dimen- 
sion. Croux et al. (2001) investigate synchronization between European countries at the frequency domain by measuring their cohesion. Cohesion measures are defined as indexes that summarize information about bilateral relations and that are useful to provide an overall assessment of the interrelations between a set of elements (markets, countries, etc.).We follow Croux et al. (2001) in computing indexes of cohesion to measure the overall degree of European synchronization. Nevertheless, our analysis differs from theirs in two important features. First, we focus on the time rather than the frequency domain and, second, we are interested in measuring cohesion based on regional rather than national disaggregation. Accordingly, our proposed time-varying European cohesion measures are defined as follows,

$$
c_{t}^{\text {europe }}=\frac{\sum_{a \neq b} \omega_{a, t} \omega_{b, t} \delta_{t}^{a b}}{\sum_{a \neq b} \omega_{a, t} \omega_{b, t}}, \text { for } a, b=1,2, \ldots, n
$$

where, $\omega_{a, t}$ and $\omega_{b, t}$ denote the weights that regions " $a$ " and " $b$ " receive, respectively, defined as the GDP share of each region with respect to the total GDP in Europe.

Figure 4 displays the time-varying European business cycle cohesion. It shows that, during the 1980s, European cohesion exhibited an upward trend. This increasing cohesion pattern is associated with the signing of the Single European Act in 1986, a treaty which forms the basis for a comprehensive program aimed at eliminating obstacles to the free movement of goods across EU borders and thus giving rise to the "single market". However, the index of European cohesion experiences a significant drop in the late 1980s. This could be associated, on the one hand, to the fall of Berlin Wall in 1989 and, on the other hand, to the early 1990s global recession. Both events lead to an increasing heterogeneity of output fluctuations across European regions around that time. ${ }^{13}$

Nevertheless, since the Maastricht Treaty was signed in 1992, European cohesion again exhibited an upward trend that continued after the introduction of the euro, in 1999, until 2007. Notice that European cohesion increased by about 5 basis points (from 0.47 to 0.52 ) between 1981 and 2007. This increase may be, at least, partially attributed to the process of European unification in institutional and economic terms. However, between 2008 and 2009 the cohesion increased dramatically by 17 basis points (from 0.52 to 0.69 ), reaching its maximum level in our sample. This leap in the cohesion was obviously influenced by the Great Recession, since contractionary business cycle shocks were propagated through

\footnotetext{
${ }^{13}$ The fall of Berlin Wall in 1989, which resulted in an important economic shock to Germany and caused a cyclical asymmetry with the rest of Europe, could also have increased heterogeneity in the transmission of business cycle shocks across European regions. In particular, the subsequent reunification process triggered an expansion and disequilibria in the German economy at a time when the main economies in the EU were decelerating.
} 
most European regions. ${ }^{14}$ These results imply that neither the Maastricht treaty nor the introduction of the euro managed to synchronize European regions in decades as much as the Great Recession did in only two years. ${ }^{15}$ Moreover, despite the fact that the cohesion index fell after the end of the Great Recession, it remained at relatively high levels until the end of our sample, in 2014, suggesting that the Great Recession had an ex-post significant impact on the regional business cycle synchronization of Europe. ${ }^{16}$

To get a better understanding about the space dimension of European regional synchronization, we measure the degree of cohesion associated with each country. This exercise will allow us to identify the countries that have contributed the most to the increasing European synchronization pattern. The time-varying cohesion of a given country $\kappa$ at time $t$ can be interpreted as a measure of country-specific internal synchronization, and it is defined as follows.

$$
c_{t}^{\kappa}=\frac{\sum_{a \neq b \in \kappa} \omega_{a, t} \omega_{b, t} \delta_{t}^{a b}}{\sum_{a \neq b \in \kappa} \omega_{a, t} \omega_{b, t}} .
$$

Chart A of Figure 5 shows the cohesion measures for central European countries (DE, NL, AT, BE), which experienced a progressive increase from 1981 until 2008 and a hike at the beginning of the Great Recession. Chart B shows the cohesion associated with Mediterranean countries (PT, ES, FR, IT, GR), showing a relatively similar pattern to the cohesion of Central countries. Most of these countries are in the eurozone, which would explain this upward trend. Amongst them, Portugal shows the lowest degree of internal synchronization during the whole sample, while Spain stands out for its high cohesion during most of the period considered. Notice that, after the Great Recession, the cohesion indexes of both central European and Mediterranean countries remained at high levels, showing that the latest global recession had long-lasting consequences for these European regions in terms of business cycle synchronization. Chart $\mathrm{C}$ plots the cohesion for the British Isles (UK, IE), which exhibit a rather different pattern. These countries underwent a significant decline in internal synchronization during the 1990s and 2000s. At the beginning of the Great Recession, the cohesion in both economies significantly increased. Finally, Chart D plots the cohesion measures of Nordic countries (FI, DK, NO, SE), showing a pattern relatively similarly to that of the British Isles. Nordic countries underwent a decreasing synchronization from the mid 1990s until 2007 -which was especially sharp for Norway after 1997 and Denmark after

\footnotetext{
${ }^{14}$ In this line, Bandres et al. (2017) compute the rolling average of spatial correlation using Moran's modified statistic for European regions. They observe that spatial correlation progressively increased during the convergence process and rocketed during the Great Recession. Their sample ends in 2011.

${ }^{15}$ This result is in line with that of Canova et al. (2012), who show that time variations in the features and the transmission of cyclical fluctuations across countries appear to be linked more to the general process of European convergence taking place since the mid-80s than to institutional changes.

${ }^{16}$ Ciccarelli et al. (2016) find that, while the Great Recession features the largest real and financial shocks, their spillovers to advanced economies were similar to those observed during previous recessions.
} 
2001. Finland is an exception as it has an overall increasing trend in internal synchronization throughout the sample, though with a very volatile profile. This may be related to the fact that Finland is the only Nordic country that is included in the eurozone. These results suggest that the pattern of increasing synchronization in Europe can be mainly attributed to the Central and Mediterranean countries, since the British Isles and Nordic countries have a different behaviour.

\subsection{The role of the economic size of regions}

In previous sections, we have analyzed the synchronization of regional GDP growth assigning the same importance to all the regions in Europe and, consequently, treating all bilateral relationship in the same way. However, some regions may play a more important role in the propagation of business cycle shocks due to their size in economic terms, i.e. their GDP share with respect to the total GDP of Europe. For example, two highly synchronized regions that also have a large economic size would act as channels in the propagation of business cycle shocks more prominently than (i) two highly synchronized regions of small economic size, or (ii) two regions of large economic size but unsynchronized. Therefore, in this section, we focus on identifying the bilateral cyclical relationships between regions that are (i) highly synchronized and (ii) large in economic size.

To identify the linkages of regions depending on their economic size, we construct a weighted measure of synchronization based on the same notion of cohesion described in Equation (18). As a consequence, our modified synchronization measure is given by

$$
\tilde{\delta}_{t}^{a b}=\frac{\left(\omega_{a, t} \omega_{b, t} \delta_{t}^{a b}\right)-\delta^{\min }}{\delta^{\max }-\delta^{\min }}
$$

where $\delta^{\text {min }}$ and $\delta^{\text {max }}$ are coefficients used to normalize $\tilde{\delta}_{t}^{a b}$ between 0 and 1 for easier interpretation and denote the minimum and maximum value of the term $\left(\omega_{a, t} \omega_{b, t} \delta_{t}^{a b}\right)$ for all $a \neq b$, and for $t=1,2, \ldots, T$, respectively. Accordingly, pairs of regions with high values of $\tilde{\delta}_{t}^{a b}$ can be interpreted as the most prominent conduits of business cycle shocks.

The upper left-hand chart of Figure 6 plots the main linkages between European regions with a weighted synchronization higher than 0.25 for 1981 . We have also assessed the results with different thresholds, but the main conclusions remain unchanged. ${ }^{17}$ This set of linkages can be viewed as a European business cycle network that has a star-shaped topological structure, in which the central region is Ile de France and the arrows around it are Inner

\footnotetext{
${ }^{17}$ Bailey et al. (2015) propose a procedure for selecting significant bilateral static correlations, computed using the entire sample. However, since our approach produces measures that can be interpreted as timevarying correlations, this selection procedure is not suitable for our case.
} 
London, some regions located in West Germany and other regions in Northern and Central Italy. It is interesting to note that the interconnections identified by our proposed weighted synchronization measure correspond very closely to the historical trade routes in Europe, located mainly in Northern Italy, the Netherlands and Ile de France. The latter used to play an important role as an articulator. ${ }^{18}$ The upper right-hand chart of Figure 6 plots the main linkages for 1999, when the euro was introduced. The chart shows a topological structure similar to that of 1981, the main difference being that, during this period, some Spanish regions became connected to Ile de France and Lombardia. These results imply that the implementation of the euro converted Spain which, at that time, was following a prolonged expansionary path, into a significant contributor to European business cycle dynamics. ${ }^{19}$ The lower left-hand chart of Figure 6 plots the main linkages for 2009, in the middle of the Great Recession. The chart shows a significantly more connected topological structure of the European business cycle network. The number of connections associated with Ile de France, Inner London and Lombardia increased notably. Some Spanish regions became connected to French, Italian and English regions, and the capital region of Greece became connected to the network. Accordingly, this chart provides a visualization of the regions that were the most prominent in propagating contractionary shocks in Europe during the Great Recession. Finally, the lower right-hand chart of Figure 6 plots the main linkages for 2014, the end of our sample. We observe that regional linkages have not changed significantly after the Great Recession, with the sole exceptions of the disconnection of Greece and the lower connectivity of some Spanish regions. Overall, these results show that Ile de France is acting as the most central region in the propagation of business cycle shocks in Europe, followed by Inner London and Lombardia.

\section{Synchronization and sectoral composition}

In previous sections, we have studied the synchronization of the European regions across time and space and have assessed the role of the economic size of regions in characterizing the propagation of business cycle shocks. In this section, we examine the role role of other factors in explaining the evolution of the synchronization between regions, paying particular attention to the similarities of their productive structure. Sectoral composition could play a significant role in explaining synchronization since it may be viewed as a proxy for the transmission channel of shocks between regions. It is worth noting that we are not investigating

\footnotetext{
${ }^{18}$ See Braudel (1979) for a detailed description.

${ }^{19}$ Notice that, during this period, the relative weight of the Spanish regions remained relatively stable, indicating an increased synchronization as the source of these linkages.
} 
a causal relationship between sectoral composition and synchronization, but looking for the degree of association between them.

The literature on synchronization has mainly focused on analyzing the role of sectoral composition in determining business cycle synchronization at country level. ${ }^{20}$ However, studies that investigate the extent to which sectoral patterns can explain regional synchronization are quite scarce and their findings are not conclusive. For example, Barrios et al. (2003) compute industrial similarity using a sample of eleven UK regions and six euro area countries for the period 1966-1997 and find that industrial similarity does not explain the decline in the UK-EU business cycle correlations. Belke and Heine (2006) test the impact of industrial structure on the regional employment cycles of thirty European regions for the period 1975-1996, finding that differences in industry structure account for the decline in employment synchronicity among regions. ${ }^{21}$ Apart from their different datasets (variables used and temporal and spatial dimensions considered), since these studies are based on simple linear regression approaches, plausible reasons for the difference in their results could be the existence of a nonlinear relationship between sectoral composition similarities and business cycle synchronization, or a potential instability in this relationship over time, or both of them. In this section, we tackle these possibilities in a parsimonious way to provide a robust assessment of the relationship between sectoral composition and business cycle synchronization at the regional level.

\subsection{Similarities in sectoral composition}

First, we quantify the degree of similarity in the bilateral sectoral composition of European regions. We compute the variable sectoral, which captures the similitude between the productive structures of the regions. We adapt the expression used by Imbs (2004) and measure sectoral composition similarity as follows,

$$
C_{t}^{a b}=1-\frac{\sum_{i=1}^{k}\left|c_{t}^{i, a}-c_{t}^{i, b}\right|}{2}
$$

where $c_{t}^{i, j}$ is the employment share of sector $i$ in region $j$ at time $t$ and $k$ the number of sectors. Given the available data, we consider 6 sectors: Agriculture, Industry, Construc-

\footnotetext{
${ }^{20}$ Clark and van Wincoop (2001) examine several measures of sectoral dissimilarity. They find that these measures explain, to some extent, the low cross-country correlation of employment between the US and the EU, but they find no correlation with the GDP. Imbs (2004) computes a specialization index of industries and identifies a low business cycle correlation between highly specialized regions.

${ }^{21}$ Barrios and De Lucio (2003) show that the more similar the sectoral structures of Spanish and Portuguese regions (1975-1998) are, the more correlated the employment cycles are.
} 
tion, Financial and business services (FBS), Non-market services, and a sector involving the following categories; Wholesale, retail, transport, accommodation, food services, information and communication (WRTAFIC). The index of sectoral composition similarities, $C_{t}^{a, b}$, ranges from 0 , when the sectoral structures of regions $a$ and $b$ are completely different, to 1 , when the sectoral structures are identical.

In Figure 7, we plot the estimated density of regional sectoral composition similarities for selected years, $\mathbf{C}_{t}=\left\{C_{t}^{a, b}: \forall a \neq b\right\}$. There is a displacement of the kernel density mass towards the right tail, which indicates an increase in sectoral similarity over time. Moreover, this has been a gradual but persistent pattern over the entire sample period (1980-2014). ${ }^{22}$ The data on sectoral composition shows that, at the beginning of the sample, in 1980, there was substantial heterogeneity in sectoral composition similarities across Europe. However, at the end of the sample, in 2014, there is a more homogeneous pattern with most of the regions exhibiting high levels of sectoral composition similarities, as can be seen in the heat maps of Figure 11 in Appendix B. ${ }^{23}$ This result has important implications for the propagation of shocks throughout the European economy, since the more similar the economic structure of regions is, the more similar their responsiveness to shocks would be, potentially amplifying their effects at the aggregate level.

\subsection{Parametric Regression Analysis}

We start analyzing the relationship between synchronization and sectoral composition by controlling for additional potential determinants of regional synchronization. To do so, we model the original synchronization measures, $\delta_{t}^{a b}$, as a function of sectoral composition, $C_{t}^{a b}$, and a set of other regressors. These regressors can be sorted into two groups. The first group corresponds to institutional and geographical factors:

- EMU: defined as a dummy that takes value 1 if both regions belong to the EMU and 0 otherwise.

- Group: defined as a dummy that takes value 1 if both regions belong to the same group of countries and 0 otherwise; the groups are defined as "Central countries" (BE, DE, FR, NL, LU, AT), "Nordic countries" (DK, SE, NO, FI), "Mediterranean countries" (GR, IT, PT, ES), "British Isles" (IE, UK).

\footnotetext{
${ }^{22}$ The associated figures for all the years in the sample are not reported in the paper to save space, but they are available upon request.

${ }^{23}$ The heat maps offer richer information if one is interested in analyzing a particular set of regions. For instance, in the map of 1980, it is possible to identify cold areas that correspond to Greek regions that report degrees of sectoral similarity around 0.3. Intermediate maps, which are not presented to save space, and the details by region are available upon request.
} 
- Country: defined as a dummy that takes value 1 if both regions belong to the same country and 0 otherwise.

The second group is related to the economic importance of the regions, proxied by their economic size:

- Size-reg: defined as the economic weight of each pair of regions: $\frac{Y_{a, t}+Y_{b, t}}{\sum_{i=1}^{n} Y_{i, t}}$, where $Y_{i}$ is the real GDP of region $i$ and $n$ is the total number of regions.

- Size-country: defined as the economic weight of the countries to which each pair of regions belong: $\frac{Z_{a, t}+Z_{b, t}}{\sum_{i=1}^{\eta} Z_{i, t}}$ where $Z_{i}$ is the real GDP of the country to which region $i$ belongs and $\eta$ is the number of countries.

Notice that the first three variables are dummies that represent geographical and institutional characteristics so they have no time dimension. However, the remaining three variables are time-varying. ${ }^{24}$

In order to account for the heterogeneity in the cross-sectional dimension and over time, we estimate a panel regression with fixed time effects. ${ }^{25}$

$$
\delta_{t}^{a b}=\beta X_{t}^{a b}+\tau_{t}+\epsilon_{t}^{a b},
$$

where $X_{t}^{a b}=\left[\right.$ Constant $_{t}^{a b}, E M U_{t}^{a b}$, Group $_{t}^{a b}$, Country $_{t}^{a b}$, Size-reg $g_{t}^{a b}$, Size-country $y_{t}^{a b}$, Sectoral $\left.l_{t}^{a b}\right]{ }^{26}$ The estimation results are reported in Table 2 and indicate that most of the explanatory factors have a positive and statistically significant relationship with the regional synchronization. In particular, Size-reg $g_{t}^{a b}$ and Sectoral $a_{t}^{a b}$ are the factors with the largest effect on synchronization. The exceptions are the $E M U_{t}^{a b}$ and Groups $_{t}^{a b}$ that have a negative relationship with synchronization, although the magnitude of the associated coefficients is almost negligible and not statistically significant for the case of Groups $s_{t}^{a b}$. Therefore, this preliminary analysis indicates that, after controlling for other factors, sectoral composition has a significant effect on explaining changes in synchronization.

\footnotetext{
${ }^{24}$ We have calculated the covariance matrix in order to discard multicolinearity problems. We find that correlations are low, except in the cases of Group and Country (0.50), Groups and EMU (0.41) and Size-country and Size-reg (0.29).

${ }^{25}$ We have tested for the presence of unit roots in the time-varying variables, synchronization and the sectoral index. The Augmented Dickey-Fuller test (Dickey and Fuller, 1979) and the Mz test of Ng and Perron (2001) do not reject the null hypothesis in almost all cases. Furthermore, we can accept the existence of cointegration between time-varying variables using the test of Phillips and Moon (1999). In any case, Phillips and Moon (1999) show that the fact that $n>>t$, as in our case, guarantees the consistency of our estimates.

${ }^{26} \mathrm{We}$ acknowledge that there could be other variables that explain synchronization, but we are interested in understanding possible associations, not causal relationships.
} 
To investigate potential instabilities over time in the relationship between regional synchronization and its driving factors, we estimate a cross-sectional regression for each time period (year) in the sample.

$$
\delta^{a b \mid t}=\beta_{t} X^{a b \mid t}+\epsilon^{a b \mid t}
$$

Accordingly, we run $T$ regressions using OLS and obtain the associated time-varying coefficients, $\beta_{t}$, for $t=1,2, \ldots, T$. The dynamics of the estimated regression coefficients for all the years are displayed in Figure 8. The results indicate that the estimated dynamic coefficients, $\widehat{\beta}_{t}$, in general, fluctuate closely around the constant estimates from the panel regression, $\widehat{\beta}$, implying that the relationship between synchronization and its explanatory factors has remained relatively stable over time. However, there are some important exceptions, especially since the Great Recession.

Of the institutional factors, EMU membership (emu) has a positive and significant effect on regional synchronization that begins in the late 1990s with the introduction of the euro, remaining high until the arrival of the Great Recession. The effect then became negative since it affected the eurozone countries with different intensities. Belonging to the same group of countries (group) does not explain, in general, regional synchronization since its coefficient is hardly ever significant, except after the Great Recession, when the effect is significantly positive. This implies that the arrival of the Great Recession triggered a stronger synchronization among regions of the same group of countries. The effect of the variable country is positive and significant only during the period between the Maastricht Treaty and the introduction of the euro, pointing to a strong intra-country synchronization during that time. ${ }^{27}$

As for economic factors, their corresponding relationships with regional synchronization have remained relatively stable over time, with the exception of the last part of the sample (Figure 8 ). After the Great Recession, the correlation between synchronization and two economic factors, size-reg and sectoral, significantly increased. These results indicate that, taking into account additional factors, the similarities of regional sectoral composition have become significantly more important in explaining regional synchronization in Europe since the Great Recession.

\footnotetext{
${ }^{27}$ Clark and van Wincoop (2001) confirm the existence of a border effect on within-country correlations (of some French and German regions) larger than that on cross-country correlations. Acedo-Montoya and de Haan (2008) find that within-country cycles are always more correlated than they are with the euro area cycle, their sample being 53 regions (12 countries). All these previous findings contradict those of Fatas (1997) who suggests than the effect of national borders has been reduced over time for 38 regions (4 countries).
} 


\subsection{Nonparametric Regression Analysis}

Previous studies have used parametric econometric approaches, similar to these described in Section 4.2, to evaluate the relationship between similarities in sectoral composition across countries and international business cycle synchronization (Imbs (2004) and Ductor and Leiva-Leon (2016)). However, when dealing with a higher level of disaggregation, e.g. at regional level, the inherent larger degree of heterogeneity in the data may lead to nonlinear relationships between the variables under study. Therefore, to provide robust assessments of the relationship between similarities in regional business cycles, $\delta_{t}^{a b}$, and similarities in regional sectoral composition, $C_{t}^{a b}$, we take advantage of the rich set of information, composed of 22,578 pairwise linkages between the 213 NUTS-2 European regions, and make minimal assumptions by employing nonparametric methods.

Our focus is on assessing the role of similarities in regional sectoral composition in explaining regional business cycle synchronization patterns and how this role has evolved over time. In doing so, we first compute the average synchronization over each possible level of sectoral composition similarity, $E_{t}\left(\delta_{t}^{a b} \mid C_{t}^{a b}=c\right)$. Notice that this conditional expectation can be calculated for each period of time, $t=1,2, \ldots, T$. To compute the conditional expectation, we use the Nadaraya-Watson estimator (Local Constant) with a Gaussian kernel. The selection of the optimal bandwidth is based on cross-validation using the Quartic kernel for each year. The results show two main features that are illustrated in Chart (a) of Figure 9. First, from the early 1980s until the late 2000s, the expected synchronization remained at moderate levels, around 0.5. However, after 2009, the average synchronization increased to levels of around 0.7. Second, before the Great Recession, the expected synchronization remained relatively constant across the different levels of sectoral composition but after the Great Recession, there has been a clear positive relationship between sectoral similarities and business cycle synchronization. ${ }^{28}$

Notice that, if $\delta^{a b}$ is independent from $C^{a b}$, then $E\left(\delta^{a b} \mid C^{a b}\right)=E\left(\delta^{a b}\right)$. Therefore, we can measure the role of sectoral similarities in explaining regional synchronization with the difference between the conditional and the unconditional expectations,

$$
\Delta_{t}^{a b}(c)=E_{t}\left(\delta_{t}^{a b} \mid C_{t}^{a b}=c\right)-E_{t}\left(\delta_{t}^{a b}\right)
$$

where the unconditional expectation is calculated as the simple cross-sectional average. Since $\Delta_{t}^{a b}(c)$ can be also computed for $t=1,2, \ldots, T$, we can investigate how the role of sectoral similarities has evolved over time. When $\Delta_{t}^{a b}(c)$ is close to zero, it means that the explanatory

\footnotetext{
${ }^{28}$ Figure 9 shows the expected synchronization conditional on the domain of sectoral similarities corresponding to the interval $[0.7,0.9]$ since most of the mass of the distribution is concentrated in that interval, as shown in Figure 7.
} 
power of sectoral similarities is negligible. Conversely, the more different $\Delta_{t}^{a b}(c)$ is from zero, the more informative sectoral similarity is to explain synchronization patterns. Chart (b) of Figure 9 plots $\Delta_{t}^{a b}(c)$ from selected years, reinforcing the evidence that the propagation of business cycle shocks among European regions has become more dependent on the regional productive structure after the Great Recession. These results are consistent with the findings in Section 4.2.

Moreover, chart (b) of Figure 9 reveals that the Great Recession triggered a nonlinear relationship between synchronization and sectoral similarities, as can be seen in $\Delta_{t}^{a b}(c)$ for $t=2009,2011,2014$. This relationship is convex for values of sectoral similarity lower than 0.8 , while it becomes concave for values of sectoral similarity higher than $0.8{ }^{29}$ This means that increases in sectoral similarity between regions that already exhibit either very similar $\left(C^{a b}>0.9\right)$ or very different $\left(C^{a b}<0.7\right)$ productive structures are expected to yield small increases in regional business cycle synchronization. However, increases in sectoral similarity between regions that exhibit moderately similar productive structure $\left(0.7<C^{a b}<0.9\right)$ are expected to yield large increases in regional business cycle synchronization. These results have important implications for the Cohesion Policy of the European Union whose main objectives are to avoid regional disparities, such as dissimilarities in regional business cycle fluctuations, and to restructure declining industrial areas. ${ }^{30}$

The non-parametric analysis has provided information about the type of relationship between $\delta^{a b}$ and $C^{a b}$, making minimal assumptions, and has allowed us to quantify the sectoral composition effect more accurately than using parametric regression analysis. This framework has also enabled us to identify the nonlinear effect of the sectoral composition hidden in linear panel data analysis or time-dependent regressions. Next, we analyze more deeply the source of this nonlinear effect. We want to identify the sector or sectors that most contribute to this nonlinear effect of sectoral composition on business cycle synchronization. To do so, we disaggregate the productive structure of the regions into the corresponding sectors, as follows,

$$
C_{t}^{i, a b}=1-\frac{\left|c_{t}^{i, a}-c_{t}^{i, b}\right|}{c_{t}^{i, a}+c_{t}^{i, b}},
$$

where $C_{t}^{i, a b}$ is the contribution of sector $i$ to the sectoral composition similarity between regions $a$ and $b$. As in the aggregate case, this index ranges from 0 to 1 , taking the value of 0 , when the shares associated with sector $i$ of regions $a$ and $b$ are radically different, and 1 when

\footnotetext{
${ }^{29}$ The figures are around 0.8 but vary depending on the year.

${ }^{30}$ For robustness, we have also estimated the conditional expectation using the Local Linear estimator proposed by Stone (1977) instead of the Local Constant method. The results are plotted in Figure 13 in Appendix B and reach the same conclusions. For a discussion of both methods see Liu (2011).
} 
the shares of sector $i$ are identical for both regions. Accordingly, we measure the contribution of similarities in each sector to explaining regional synchronization by computing,

$$
\Delta_{t}^{i, a b}(c)=E_{t}\left(\delta_{t}^{a b} \mid C_{t}^{i, a b}=c^{i}\right)-E_{t}\left(\delta_{t}^{a b}\right)
$$

for $i=$ Agriculture, Industry, Construction, WRTAFIC, FBS, NM services. In order to provide a full characterization of the contribution of each sector for each period of time, we use 3-D plots. Figure 10 shows $\Delta_{t}^{i, a b}(c)$ estimated with the Local Constant method for $t=1,2, \ldots, T$. The figure indicates that the indexes $\Delta_{t}^{i, a b}(c)$ associated with the sectors of Agriculture, Industry and Construction have an almost flat pattern around zero, while, the indexes associated with the sectors of Wholesale, retail, transport, accommodation and food services, information and communication (WRTAFIC), Financial and business services (FBS), and Non-market services exhibit a nonlinear pattern, especially after 2009. This result means that the increase in the power of sectoral composition to explain European regional synchronization since the Great Recession is mainly associated with the similarity between services-related industries. ${ }^{31}$

\section{Conclusions}

In this paper, we analyze changes, across time and space, in the synchronization of European regional business cycles and investigate the role of sectoral composition and other explanatory factors in explaining these changes. We also identify the regions that act as the main conduits of business cycle shocks. Our sample has a wider and more disaggregated geographical and temporal coverage than previous literature. To deal with regional data characteristics, we propose a new method to measure time-varying synchronization in small samples that combines regime-switching models and dynamic model averaging. The reliability of the proposed method is validated with Monte Carlo experiments.

The main results show that neither the Maastricht treaty nor the introduction of the euro managed to synchronize European regions in decades as much as the Great Recession did in only two years. Moreover, we show that this increase in synchronization was not temporary because regional interdependence has remained at much higher levels after the end of the Great Recession. The pattern of increasing synchronization in Europe can be mainly attributed to the Central and Mediterranean countries since the British Isles and Nordic countries have a different behaviour. The results also show that Ile de France acts as the most central region in the propagation of business cycle shocks in Europe, followed by

\footnotetext{
${ }^{31}$ We also perform the same exercise using the Local Linear estimator, but the results remain unchanged, as can be seen in Figure 13 in Appendix B.
} 
Inner London and Lombardia. When assessing the drivers of synchronization, we find that the similarities of regional sectoral composition have become significantly more important in explaining regional synchronization in Europe since the Great Recession. Moreover, the Great Recession triggered a nonlinear relationship between synchronization and sectoral similarities, which is mainly associated with the similarity between services-related industries.

Our findings provide crucial information for policymakers in the implementation of the Cohesion Policy as we not only offer a comprehensive framework of regional dynamics in the last three decades but also determine which economic regions are the most sensitive to policy changes or shocks. 


\section{References}

[1] Acedo-Montoya, L.A. and de Haan, J. (2008). Regional Business Cycle Synchronization in Europe?, International Economics and Economic Policy, 5(1-2), 123-137.

[2] Bandres, E., Gadea-Rivas, M.D. and Gomez-Loscos, A. (2017). Regional Business Cycles Across Europe. Occasional Paper no. 1702, Bank of Spain.

[3] Barrios S. and De Lucio, J.J. (2003). Economic integration and regional business cycles: evidence from the Iberian regions. Oxford Bulletin of Economics and Statistics, 65, $497-515$.

[4] Barrios, S., Brulhart, M., Elliott, R.J.R. and Sensier, M. (2003). A Tale of Two Cycles: Co-fluctuations Between UK Regions and the Euro Zone. The Manchester School, 71(3), 265-292.

[5] Bailey, N., Holly, S. and Pesaran, M. H. (2016). A Two-Stage Approach to SpatioTemporal Analysis with Strong and Weak Cross? Sectional Dependence. Journal of Applied Econometrics, 31(1), 249-280.

[6] Belke, A. and Heine, J. (2006). Specialization patterns and the synchronicity of regional employment cycles in Europe. International Economics and Economic Policy, 3, 91-104.

[7] Bengoechea, P., Camacho, M. and Perez-Quiros, G. (2006). A useful tool for forecasting the Euro-area business cycle phases. International Journal of Forecasting, 22, 735-749.

[8] Braudel, F. 1979. Civilization matrielle, conomie et capitalisme. XV-XVIII siecle. Tome 2.- Les jeux de l'Echange. Librairie Armand Colin, Paris.

[9] Camacho, M. and Leiva-Leon, D. (2016). The Propagation of Industrial Business Cycles. Macroeconomic Dynamics, Forthcoming.

[10] Camacho, M., Perez-Quiros, G. and Saiz, L. (2006). Are business cycles close enough to be just one?. Journal of Economic Dynamics and Control, 30, 1687-1706.

[11] Canova, F., Ciccarelli, M. and Ortega, E. (2012). Do institutional changes affect business cycles? Evidence from Europe. Journal of Economic Dynamics and Control, 36(10), 1520-1533.

[12] Clark, T. E. and van Wincoop, E. (2001). Borders and business cycles. Journal of International Economics, 55, 59-85. 
[13] Ciccarelli, M., Ortega, E., and Valderrama, M. (2016). Commonalities and cross-country spillovers in macroeconomic-financial linkages. BE Journal of Macroeconomics, 16(1), $231-275$.

[14] Croux, C., Forni, M., and Reichlin, L. (2001). A Measure of Comovement for Economic Variables: Theory and Empirics. Review of Economics and Statistics, 83(2), 232-241.

[15] de Haan, J., R. Inklaar, and Richard, J. (2008). Will business cycles in the Euro Area converge: a critical survey of empirical research, Journal of Economic Surveys, 22(2), $234-273$.

[16] Del Negro, M., and Otrok, C. (2008). Dynamic Factor Models with Time-Varying Parameters: Measuring Changes in International Business Cycles. Federal Reserve Bank of New York Staff Reports no. 326.

[17] Ductor, D., and Leiva-Leon, D. (2016). Dynamics of Global Business Cycle Interdependence, Journal of International Economics, 102, 110-127.

[18] Fatas, A. (1997). Countries or regions? Lessons from the EMS experience. European Economic Review, 41, 743-751.

[19] Gadea, M., Gomez-Loscos, A, and Montañes, A. (2012). Cycles inside cycles: Spanish regional aggregation, SERIEs, Spanish Economic Association, 3(4), 423-456.

[20] Giannone, D., Lenza, M. and Reichlin, L. (2010). Business Cycles in the Euro Area in Europe and the Euro, Ed. Alesina, A. and Giavazzi, F., 141-167. The University of Chicago Press.

[21] Guerin, P. and Leiva-Leon, D. (2015). Model Averaging in Markov-Switching Models: Predicting National Recessions with regional Data. Bank of Canada Working Paper $2015-24$.

[22] Hamilton, J. and Owyang, M. (2012). The Propagation of Regional Recessions. Review of Economics and Statistics. 94:4, 935-947.

[23] Harding, D. and Pagan, A. (2006). Synchronization of cycles. Journal of Econometrics. $132: 1,59-79$.

[24] Imbs, J. (2004) Trade, Finance, Specialisation and Synchronisation, Review of Economics and Statistics, 86(3), 723-734. 
[25] IMF (2009). World Economic Outlook - April 2009: Crisis and Recovery, International Monetary Fund.

[26] Koenker, R. (2004). Quantile regression for longitudinal data, Journal of Multivariate Analysis, 91(1), 74-89.

[27] Koop, G. (2014). Forecasting with dimension switching VARs. International Journal of Forecasting, 30(2), 280-290.

[28] Koop, G. and Korobilis, D. (2012). Forecasting Inflation Using Dynamic Model Averaging. International Economic Review, 53(3), 867-886.

[29] Koop, G. and Korobilis, D. (2013). Large time-varying parameter VARs. Journal of Econometrics, 177(2), 185-198.

[30] Kose, M.A., Otrok, C. and Prasad, E. (2012). Global Business Cycles: Convergence or Decoupling? International Economic Review, 53(2), 511-538.

[31] Leiva-Leon, D. (2016), Measuring Business Cycles Intra-Synchronization in US. A Regime-Switching Interdependence Framework. Oxford Bulletin of Economics and Statistics, Forthcoming.

[32] Liu, Ch. A. (2011), Averaging Estimators for Kernel Regressions. University of Wisconsin-Madison Working Paper.

[33] Marino, F. (2013). Regional fluctuations and national cohesion in the EU12: a preMaastricht assessment, SERIES Working Papers 48, University of Bari.

[34] Ozyurt, S. and Dees, S. (2015). Regional dynamics of economic performance in the EU: To what extent spatial spillovers matter?, European Central Bank Working Paper 1870.

[35] Phillips, K. (1991). A Two-Country Model of Stochastic Output with Changes in Regime. Journal of International Economics, 3, 121-142.

[36] Phillips, P. C. B. and Moon, H. R. (1999). Linear Regression Limit Theory for Nonstationary Panel Data. Econometrica, 67(5), 1057-1111.

[37] Quah, D. T. (1996). Regional convergence clusters across Europe, European Economic Review, 40, 951-958.

[38] Raftery, A., Karny, M., and Ettler, P. (2010). Online Predictions Under Model Uncertainty Via Dynamic Model Averaging: Application to a Cold Rolling Mill. Technometrics, 52, 52-66. 
[39] Ramajo, J., Marquez, M.A., Hewings, G. and Salinas, M.M. (2008). Spatial heterogeneity and interregional spillovers in the European Union: Do cohesion policies encourage convergence across regions?, European Economic Review, 52, 551-567.

[40] Rodriguez-Pose, A. (2013). Do Institutions Matter for Regional Development?, Regional Studies, 47(7), 1034-1047.

[41] Sala-i-Martin, X. (1996). Regional cohesion: Evidence and theories of regional growth and convergence, European Economic Review, 40, 1325-1352.

[42] Stone, C.J. (1977). Consistent nonparametric regression. Annals of Statistics 5, 595-620. 


\section{Tables}

\begin{tabular}{cccccccc}
\hline \hline $\bar{\mu}$ & $\sigma^{2}$ & \multicolumn{2}{c}{$T=30$} & \multicolumn{2}{c}{$T=50$} & \multicolumn{2}{c}{$T=70$} \\
\hline & & $Q P S_{d}$ & $Q P S_{\delta}$ & $Q P S_{d}$ & $Q P S_{\delta}$ & $Q P S_{d}$ & $Q P S_{\delta}$ \\
\hline 0.5 & 0.5 & 0.30 & $\mathbf{0 . 2 5}$ & 0.29 & $\mathbf{0 . 2 3}$ & 0.28 & $\mathbf{0 . 2 3}$ \\
0.5 & 1 & 0.29 & $\mathbf{0 . 2 5}$ & 0.29 & $\mathbf{0 . 2 4}$ & 0.29 & $\mathbf{0 . 2 4}$ \\
0.5 & 2 & 0.29 & $\mathbf{0 . 2 5}$ & 0.30 & $\mathbf{0 . 2 5}$ & 0.29 & $\mathbf{0 . 2 4}$ \\
1 & 0.5 & 0.23 & $\mathbf{0 . 2 1}$ & $\mathbf{0 . 1 8}$ & 0.19 & $\mathbf{0 . 1 4}$ & 0.17 \\
1 & 1 & 0.27 & $\mathbf{0 . 2 3}$ & 0.25 & $\mathbf{0 . 2 2}$ & 0.23 & $\mathbf{0 . 2 0}$ \\
1 & 2 & 0.28 & $\mathbf{0 . 2 4}$ & 0.27 & $\mathbf{0 . 2 3}$ & 0.27 & $\mathbf{0 . 2 3}$ \\
2 & 0.5 & $\mathbf{0 . 1 3}$ & 0.18 & $\mathbf{0 . 1 0}$ & 0.17 & $\mathbf{0 . 0 9}$ & 0.17 \\
2 & 1 & $\mathbf{0 . 1 8}$ & 0.19 & $\mathbf{0 . 1 2}$ & 0.17 & $\mathbf{0 . 0 9}$ & 0.17 \\
2 & 2 & 0.24 & $\mathbf{0 . 2 2}$ & 0.19 & $\mathbf{0 . 1 9}$ & $\mathbf{0 . 1 6}$ & 0.18 \\
\hline \multicolumn{9}{c}{$T=100$} & $T=200$ & $T=400$ \\
\hline 0.5 & 0.5 & 0.27 & $\mathbf{0 . 2 3}$ & 0.26 & $\mathbf{0 . 2 1}$ & 0.22 & $\mathbf{0 . 2 1}$ \\
0.5 & 1 & 0.29 & $\mathbf{0 . 2 4}$ & 0.27 & $\mathbf{0 . 2 3}$ & 0.26 & $\mathbf{0 . 2 3}$ \\
0.5 & 2 & 0.29 & $\mathbf{0 . 2 4}$ & 0.29 & $\mathbf{0 . 2 4}$ & 0.28 & $\mathbf{0 . 2 3}$ \\
1 & 0.5 & $\mathbf{0 . 1 1}$ & 0.17 & $\mathbf{0 . 0 6}$ & 0.17 & $\mathbf{0 . 0 3}$ & 0.17 \\
1 & 1 & 0.21 & $\mathbf{0 . 1 9}$ & $\mathbf{0 . 1 6}$ & 0.17 & $\mathbf{0 . 0 8}$ & 0.16 \\
1 & 2 & 0.26 & $\mathbf{0 . 2 2}$ & 0.25 & $\mathbf{0 . 2 1}$ & 0.22 & $\mathbf{0 . 2 0}$ \\
2 & 0.5 & $\mathbf{0 . 0 7}$ & 0.17 & $\mathbf{0 . 0 4}$ & 0.17 & $\mathbf{0 . 0 2}$ & 0.17 \\
2 & 1 & $\mathbf{0 . 0 8}$ & 0.17 & $\mathbf{0 . 0 4}$ & 0.17 & $\mathbf{0 . 0 2}$ & 0.17 \\
2 & 2 & $\mathbf{0 . 1 2}$ & 0.17 & $\mathbf{0 . 0 6}$ & 0.17 & $\mathbf{0 . 0 3}$ & 0.17 \\
\hline \hline
\end{tabular}

Table 1: Simulation results

Note. The table reports the average QPS for the forgetting factor method $(\delta)$ and the Markov-chain method $(d)$. Results are based on 1,000 replications.

\begin{tabular}{lcc}
\hline \hline variables & coeff & t-ratio \\
\hline constant & 0.3726 & 113.5594 \\
emu & -0.0026 & -3.3216 \\
groups & -0.0013 & -1.6257 \\
country & 0.0451 & 33.4649 \\
size-regions & 0.9623 & 22.6448 \\
size-countries & 0.0195 & 5.6318 \\
sectoral & 0.1142 & 30.8652 \\
\hline \hline
\end{tabular}

Table 2: Estimation of panel

Note. Standard errors are HAC robust and fixed time effects are included. 


\section{Figures}

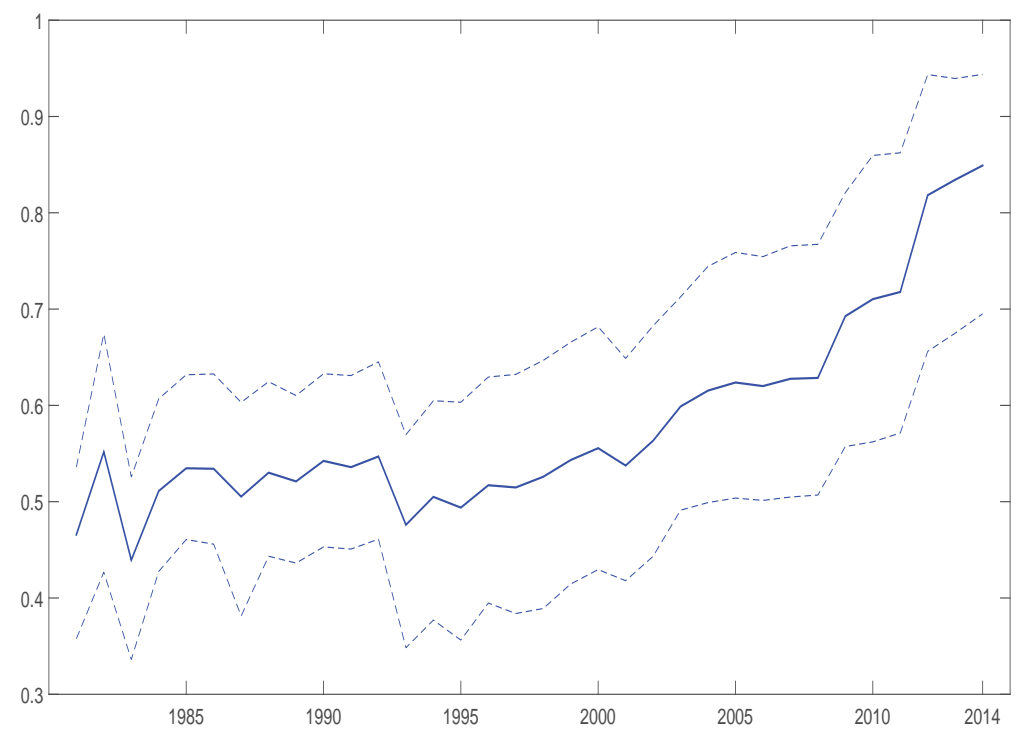

(a) Brussels-Capital vs. Noord-Holland

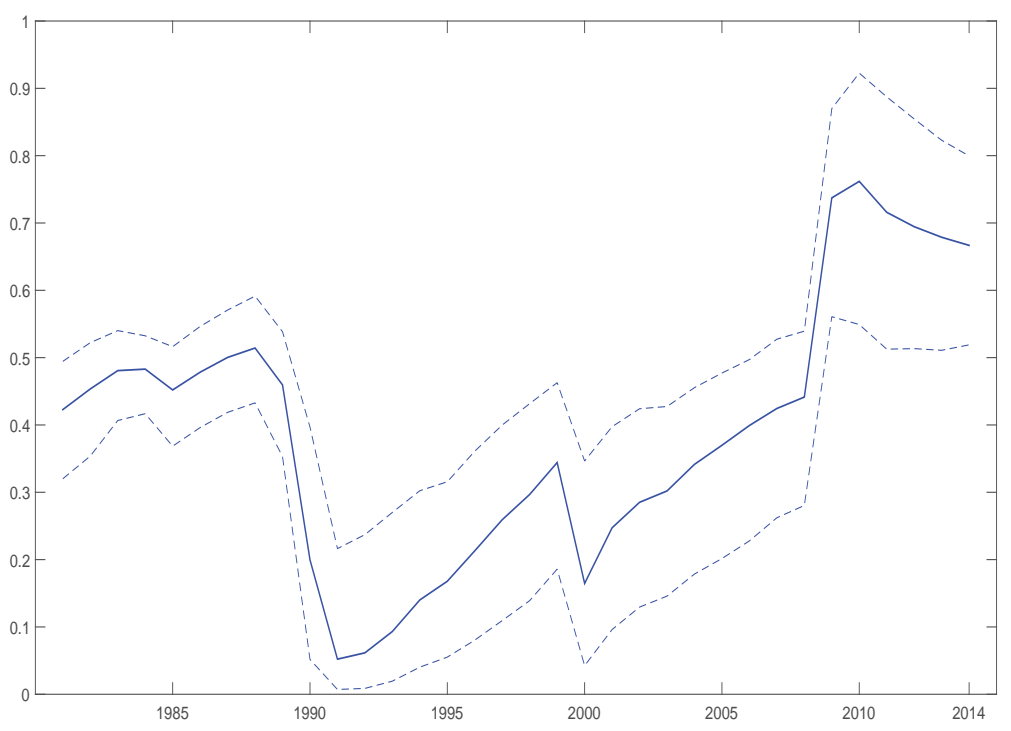

(b) Ile de France vs. Inner London

Figure 1: Time-varying regional business cycle synchronization

Note. The figure plots the time-varying synchronization between pairs of European regions. Solid lines represent the 0.5 quantile and dashed lines represent the 0.75 and 0.25 quantiles of the distribution of $\delta_{t}^{a b}$. 


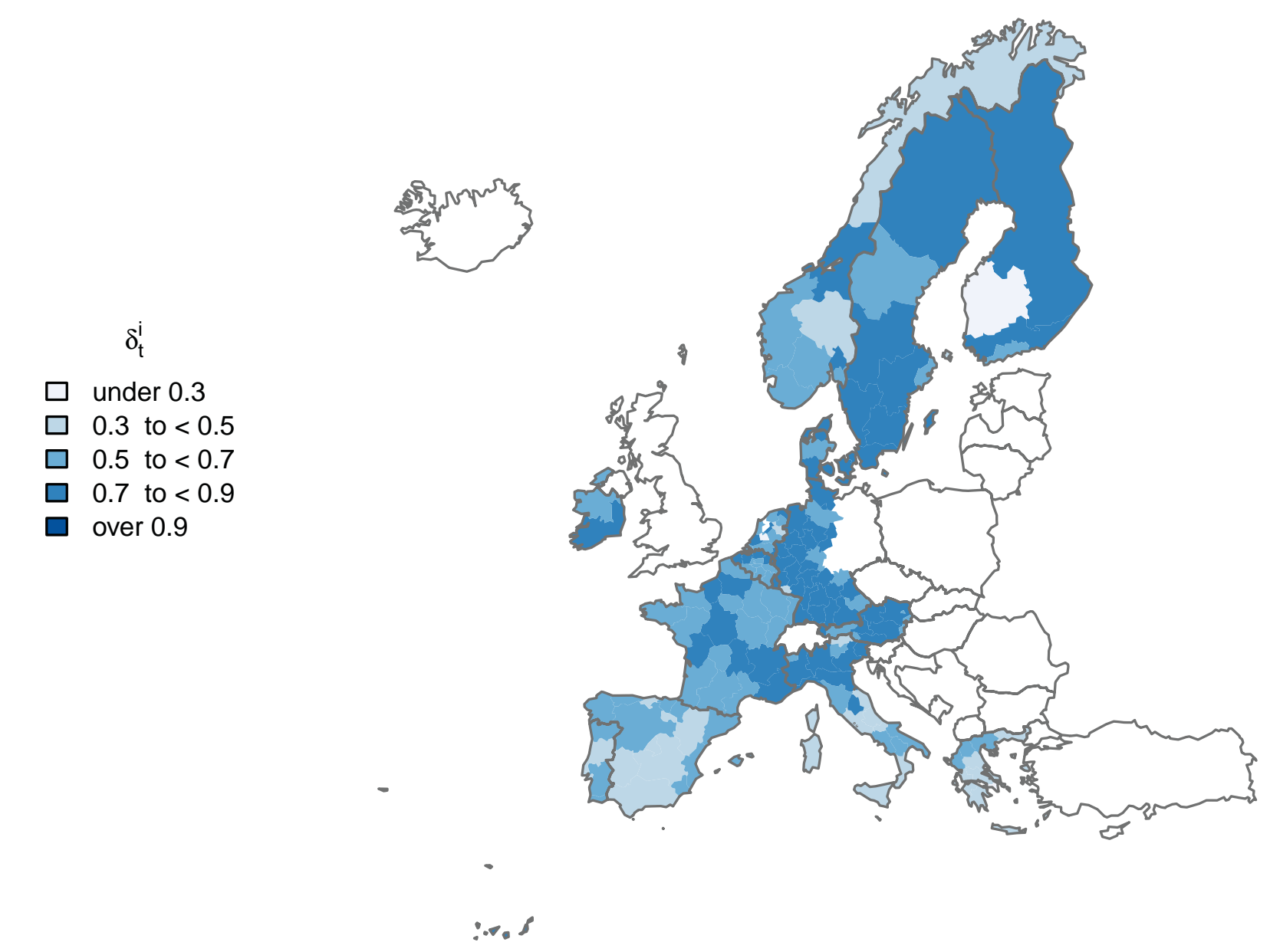

Figure 2: Synchronization between United Kingdom and the rest of Europe in 2014

Note. The figure plots a heatmap that shows the strength of the business cycle synchronization between the UK (as a whole) and the European regions. The darker (lighter) each region is, the higher (lower) its synchronization with the UK is. 

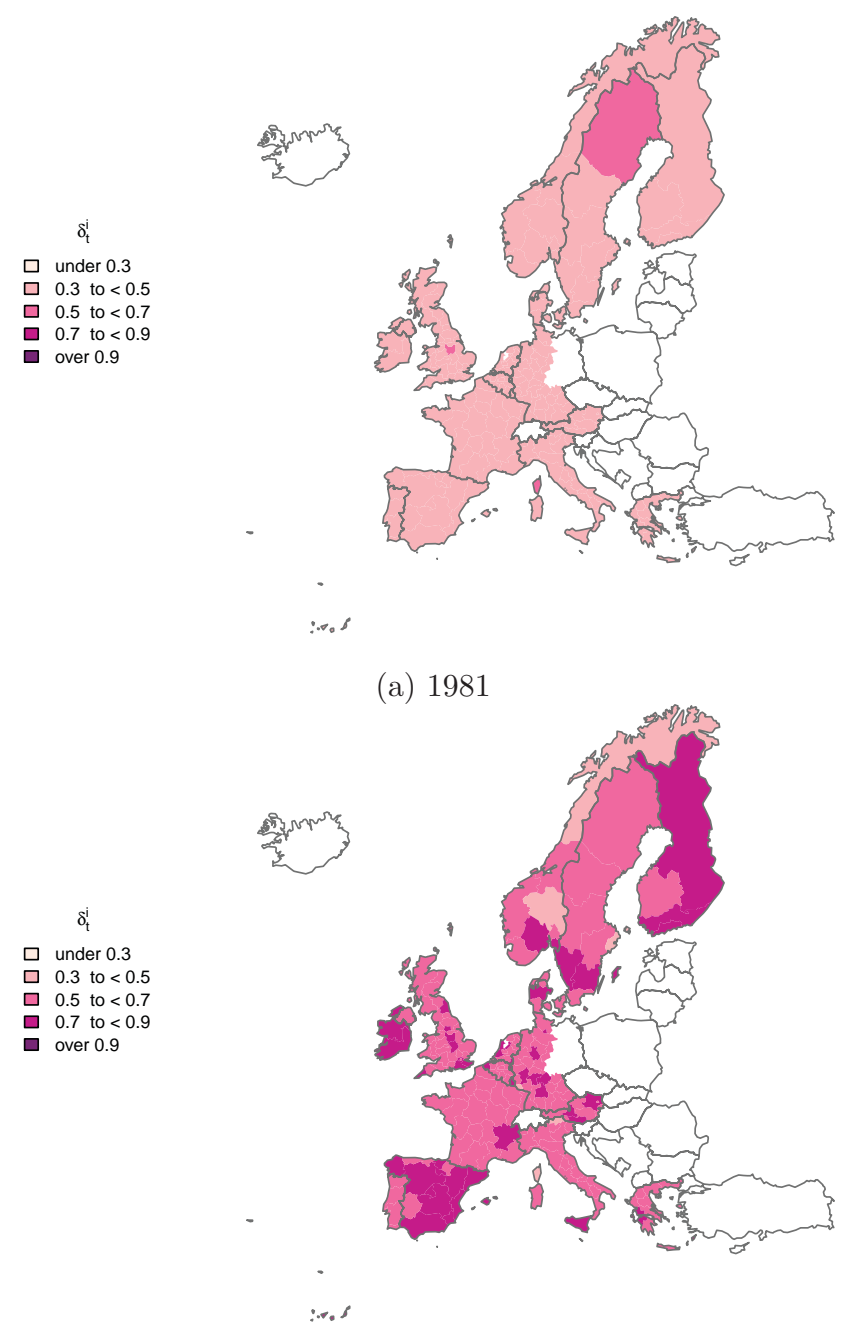

(c) 2009
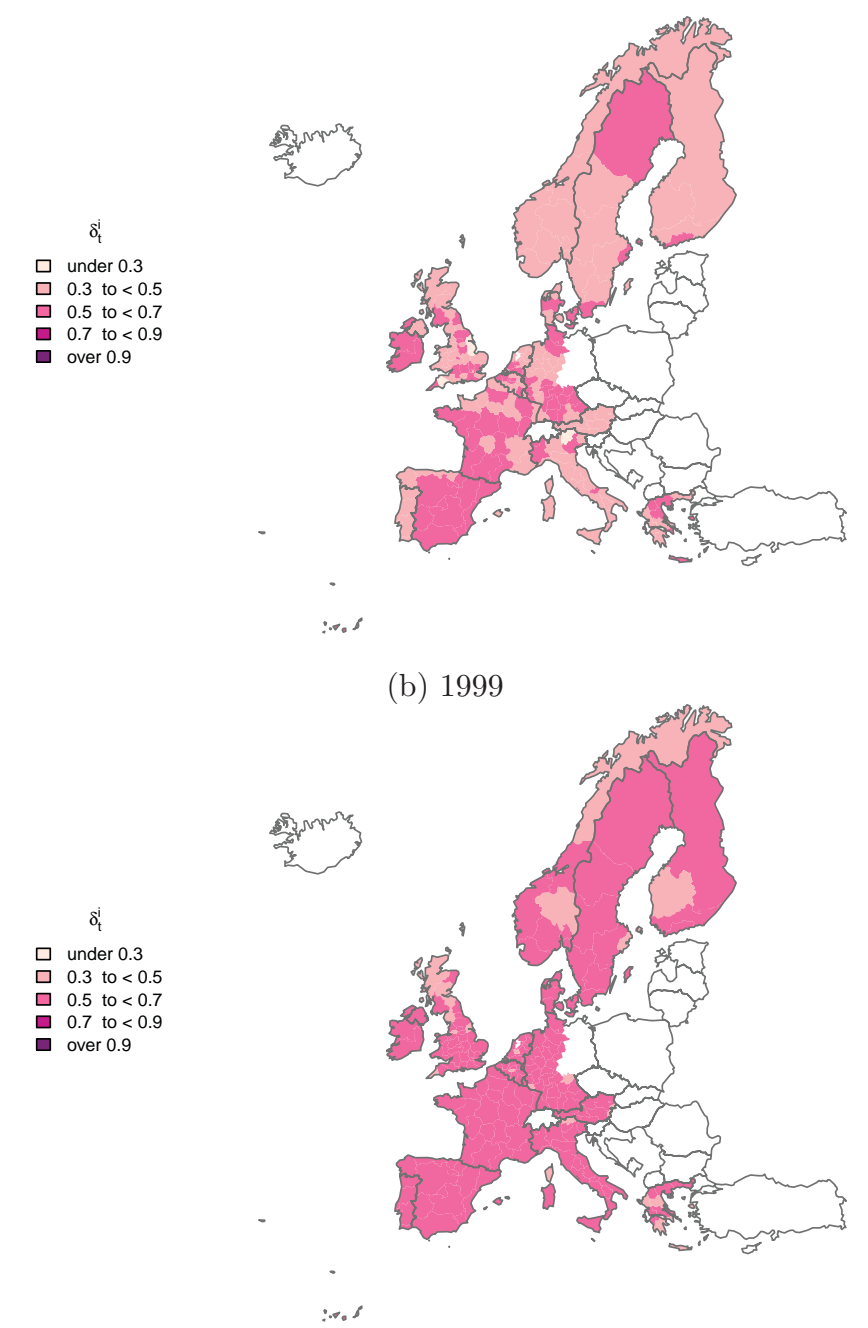

(d) 2014

Figure 3: Regional business cycle synchronization patterns

Note. Each chart plots a heatmap that shows the strength of the business cycle synchronization between each region and the rest of Europe for a selected period of time. The darker (lighter) each region is, the higher (lower) the synchronization with the UK is. Overseas regions of France and Portugal are not displayed because of the dimensions of the map. 


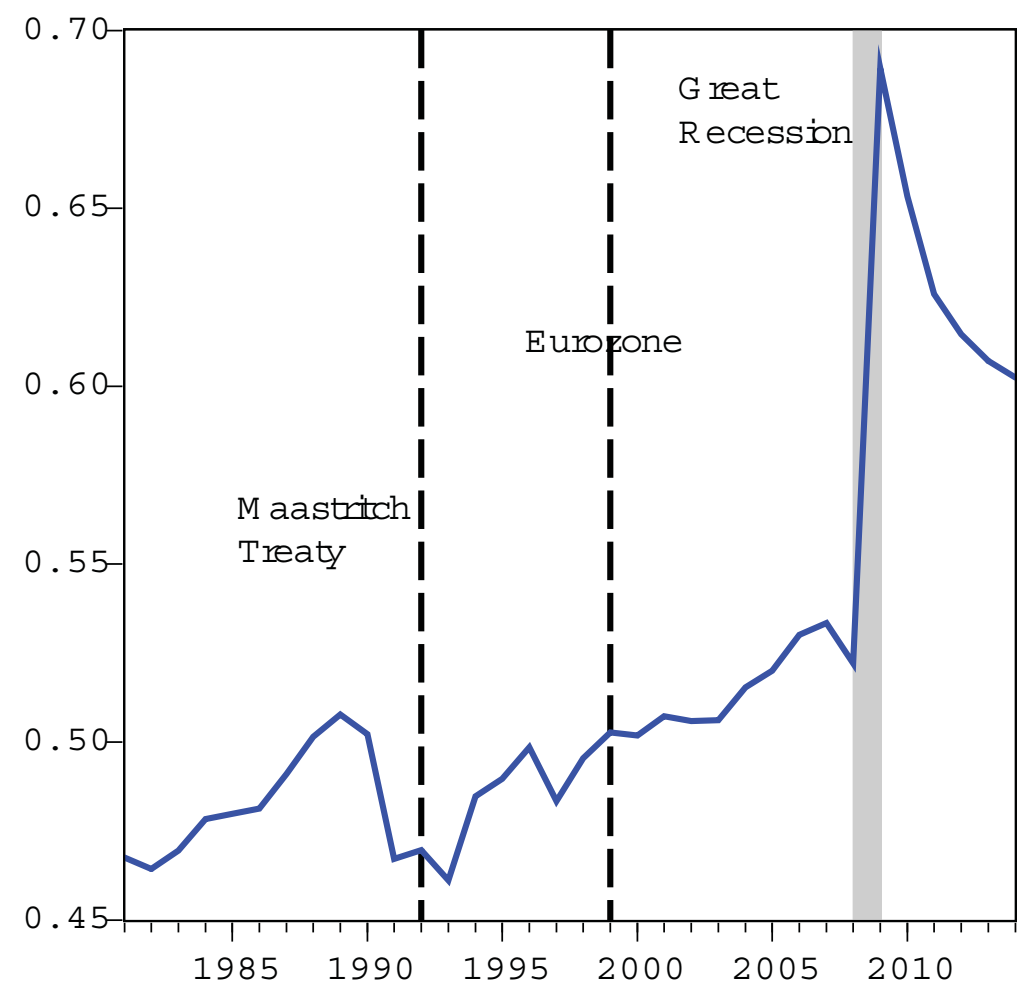

Figure 4: Time-varying European cohesion

Note. The figure plots the European cohesion measure over time. Vertical lines and bars refer to specific events. 


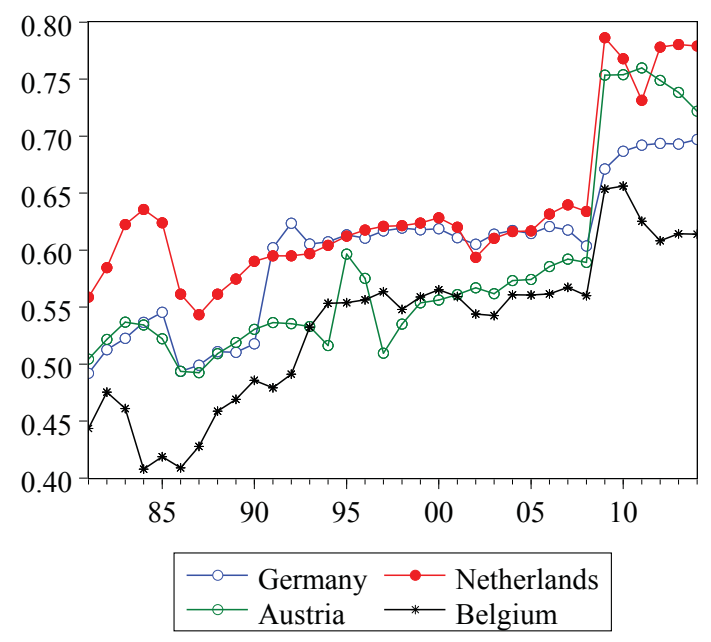

(a)

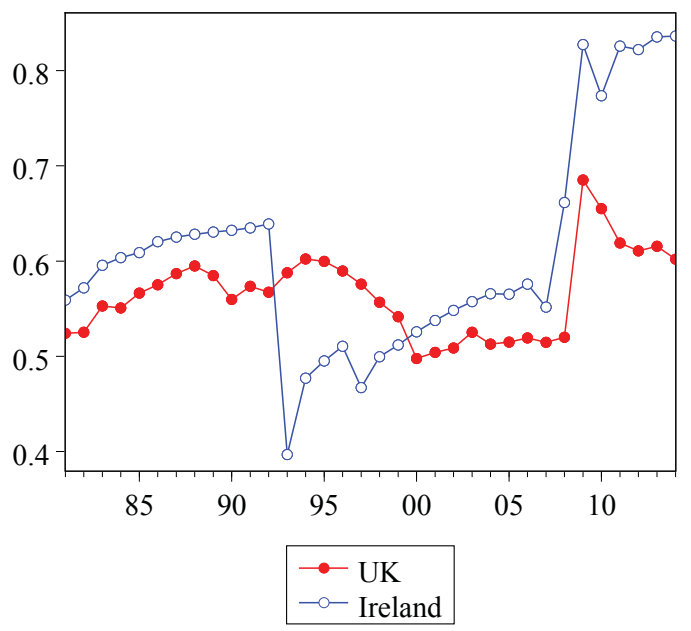

(c)

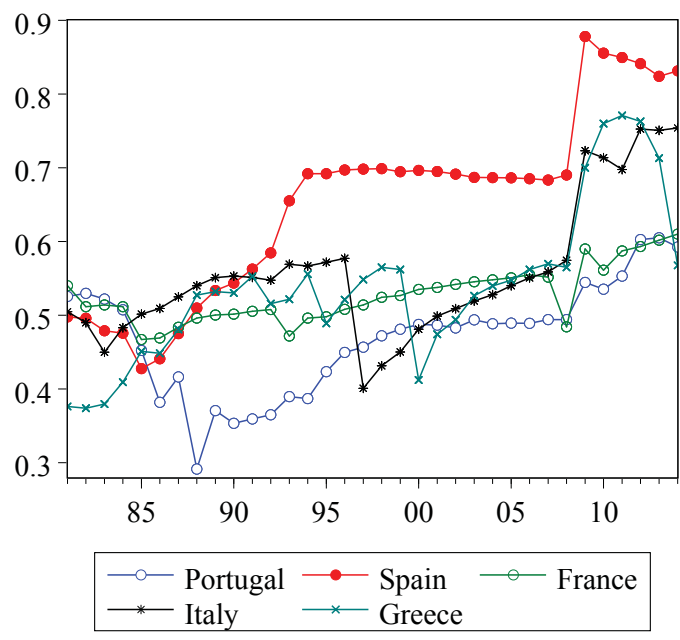

(b)

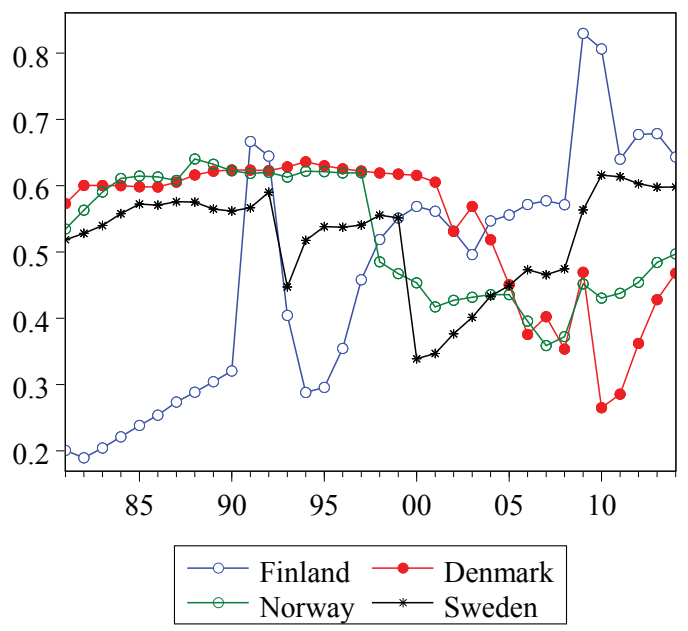

(d)

Figure 5: Time-varying country-specific cohesion

Note. The figure plots the time-varying cohesion measures for each European country grouped in charts based on their geographic proximity. 
1981

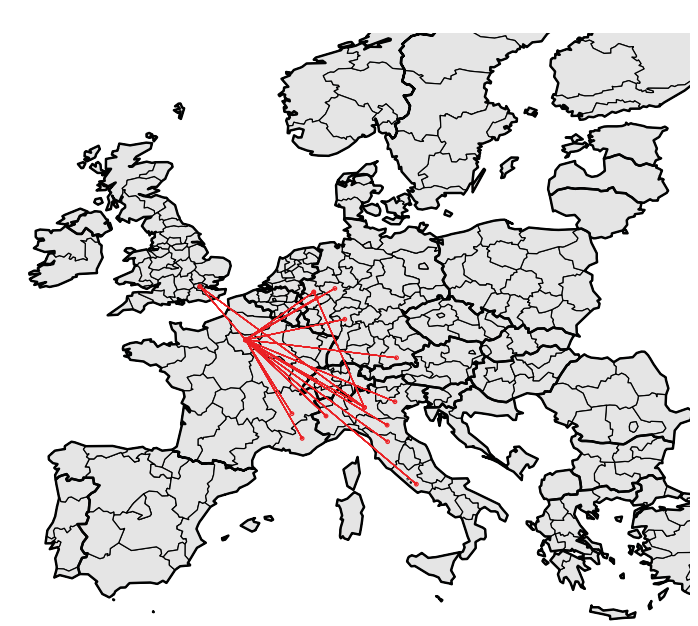

1999
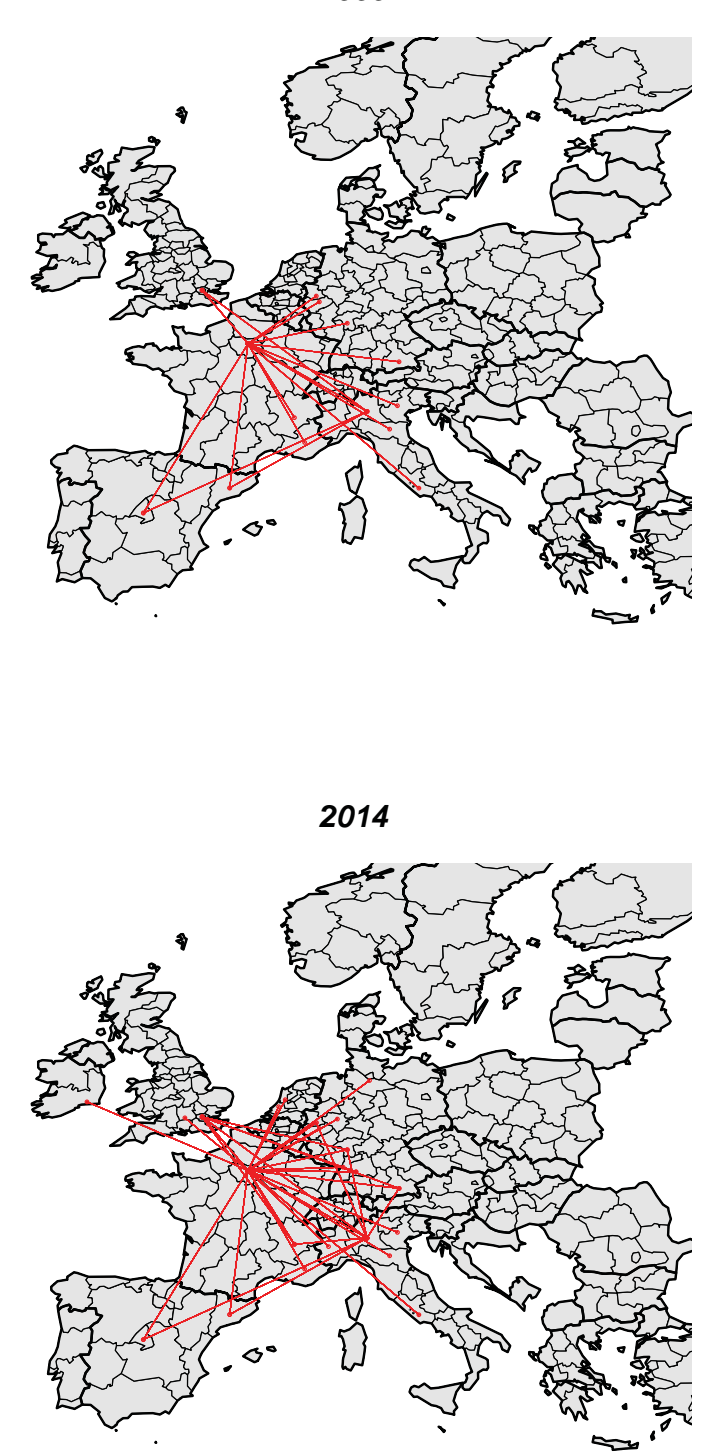

Figure 6: Main European regional economic linkages

Note. A red line connecting two regions indicates a weighted synchronization higher than or equal to 0.25 between them. 


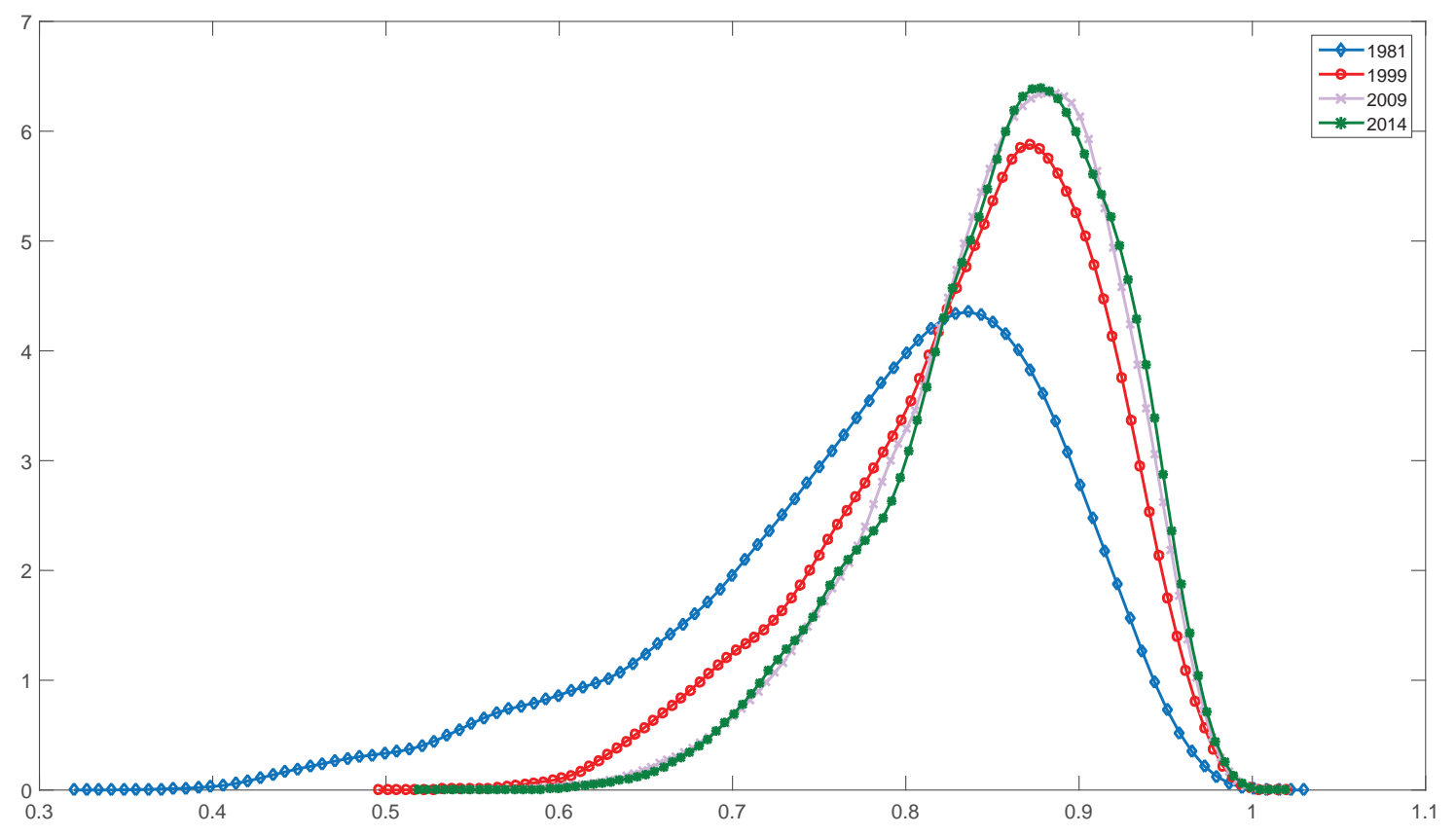

Figure 7: Density of regional sectoral composition similarities

Note. The figure plots the kernel estimates of the distribution of sectoral composition similarities across the European regions for selected periods. Sectoral similarity is measured following Imbs (2004). 

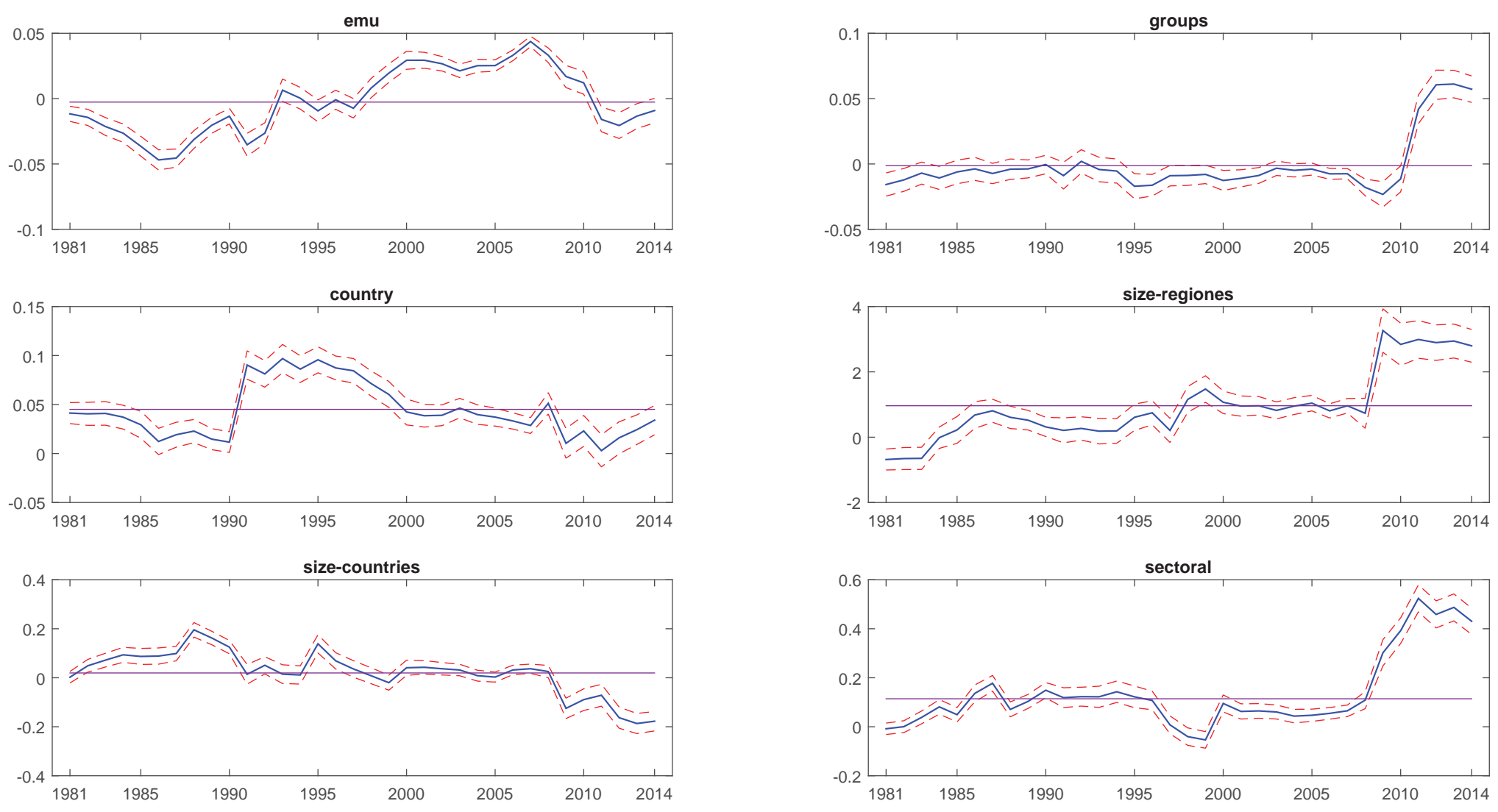

Figure 8: Coefficients and confidence intervals of time regressions

Notes. For each chart, solid blue lines represent the estimated time-varying betas and the red dashed lines show the $95 \%$ confidence intervals. The solid horizontal purple line represents the estimated coefficient obtained from the panel data model (constant beta). 


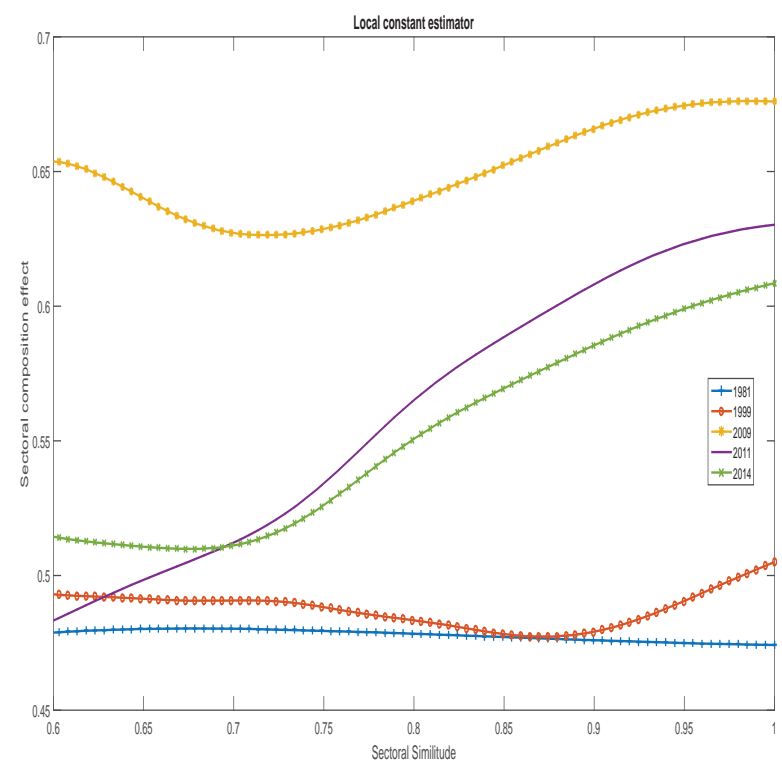

(a) Conditional mean

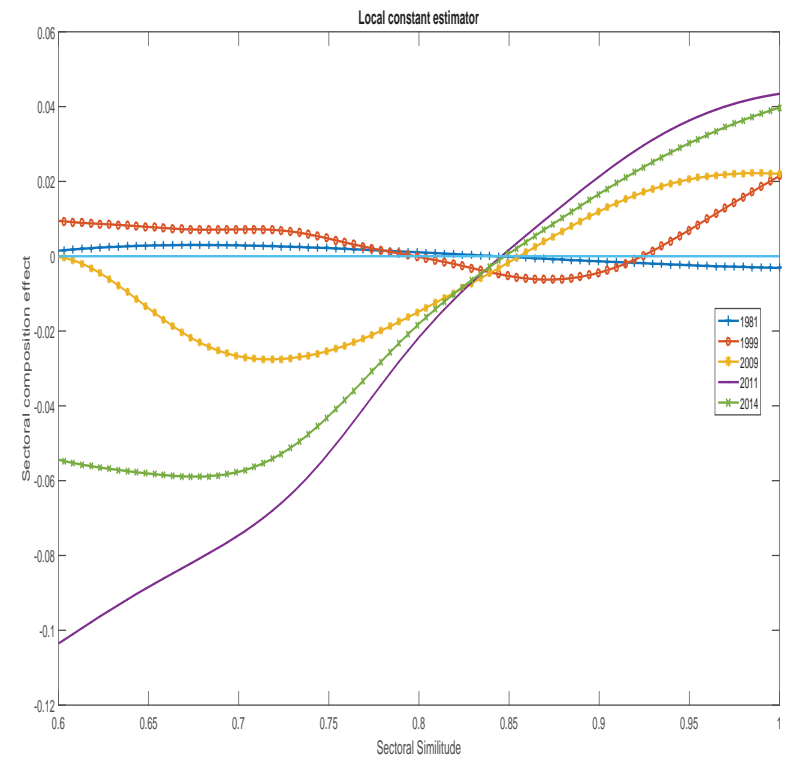

(b) Conditional minus unconditional mean

Figure 9: Expected synchronization conditional on sectoral similarity

Note. Chart (a) shows the conditional expectation of synchronization for selected periods of time, that is, $E_{t}\left(\delta_{t}^{a b} \mid C_{t}^{a b}=c\right)$. Chart (b) shows the conditional minus the unconditional expectation of synchronization for selected periods of time, that is, $\Delta_{t}^{a b}=E_{t}\left(\delta_{t}^{a b} \mid C_{t}^{a b}=c\right)-E_{t}\left(\delta_{t}^{a b}\right)$. 

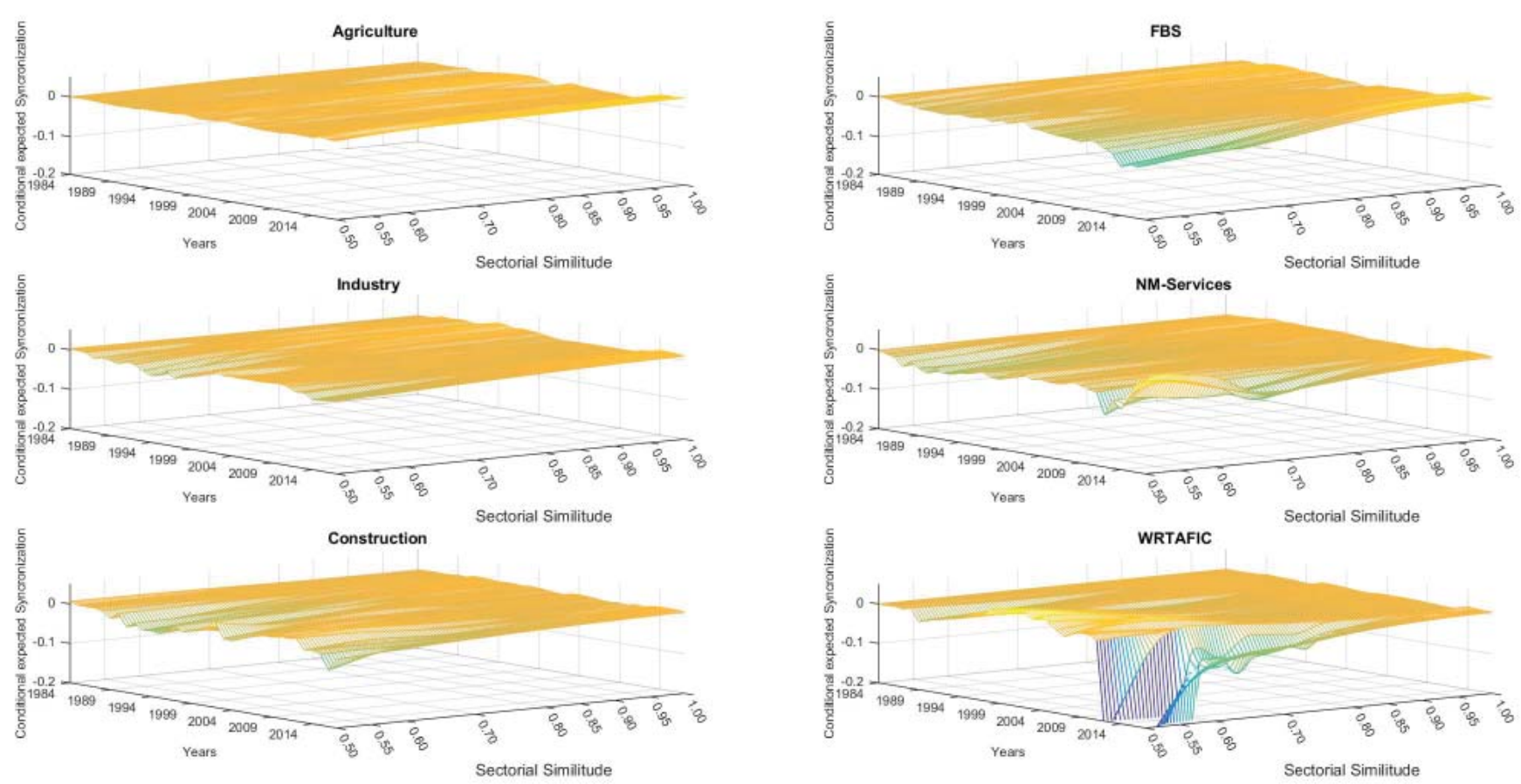

Figure 10: Disaggregated local constant estimators

Note. The charts show the conditional minus the unconditional expectation of synchronization over time for different sectors. 


\section{Appendix A}

\section{Priors}

For the mean and variance parameters in vector $\theta$, the independent Normal-Wishart prior distribution is used:

$$
p\left(\mu, \Sigma^{-1}\right)=p(\mu) p\left(\Sigma^{-1}\right)
$$

where

$$
\begin{aligned}
\mu & \sim N\left(\underline{\mu}, \underline{V}_{\mu}\right) \\
\Sigma^{-1} & \sim W\left(\underline{S}^{-1}, \underline{v}\right),
\end{aligned}
$$

and the associated hyperparameters are given by $\underline{\mu}=(-1,2-1,2)^{\prime}, \underline{V}_{\mu}=I, \underline{S}^{-1}=I$, $\underline{v}=0 . .^{32}$

For the transition probabilities $p_{a, 00}, p_{a, 11}$, of $S_{a, t}, p_{b, 00}, p_{b, 11}$, of $S_{b, t}$, and $p_{00}, p_{11}$, of $S_{t}$, Beta distributions are used as conjugate priors:

$$
\begin{aligned}
p_{k, 00} & \sim \operatorname{Be}\left(u_{k, 11}, u_{k, 10}\right), p_{k, 11} \sim \operatorname{Be}\left(u_{k, 00}, u_{k, 01}\right), \text { for } k=a, b \\
p_{00} & \sim \operatorname{Be}\left(u_{11}, u_{10}\right), p_{11} \sim \operatorname{Be}\left(u_{00}, u_{01}\right),
\end{aligned}
$$

where the hyperparameters are given by $u_{a, 01}=u_{b, 01}=u_{01}=2, u_{a, 00}=u_{b, 00}=u_{00}=8$, $u_{a, 10}=u_{b, 10}=u_{10}=1$ and $u_{a, 11}=u_{b, 11}=u_{11}=9$.

To be able to generate draws of the forgetting factor, we linearize the equation associated with the dynamics of $\tilde{\delta}_{T}$ and treat it as a linear regression, for which we use a Normal-Gamma prior distribution given by:

$$
\begin{aligned}
\alpha & \sim N\left(\underline{\alpha}, \underline{\sigma}_{\alpha}\right) \\
\sigma_{\delta}^{-1} & \sim G\left(\underline{s}^{-1}, \underline{v}\right),
\end{aligned}
$$

with hyperparameters associated with the Normal distribution, $\underline{\alpha}=0.9, \underline{\sigma}_{\alpha}=0.1$, and with the Gamma distribution, $s^{-1}=0, \underline{v}=0$.

\footnotetext{
${ }^{32}$ For the empirical application, due to the substantial heterogeneity in the magnitude of growth rates at the regional level, we use $\mu=\left(\mu_{a^{-}}, \mu_{a^{+}}, \mu_{b^{-}}, \mu_{b^{+}}\right)$as hyperparameter priors for the means, where $\mu_{\iota^{-}}$and $\mu_{\iota^{+}}$are the means of positive and negative values of $y_{\iota, t}$, respectively, for $\iota=a, b$.
} 


\section{Gibss sampler}

Draw $\tilde{S}_{a, T}, \tilde{S}_{b, T}, \tilde{S}_{T}, \tilde{\delta}_{T}$.

In order to make inferences about the variables $\tilde{S}_{a, T}, \tilde{S}_{b, T}, \tilde{S}_{T}$ and $\tilde{\delta}_{T}$, we follow the line of Kim and Nelson (1999) and compute draws from the conditional distributions:

$$
\begin{aligned}
g\left(\tilde{S}_{k, T} \mid \theta, \tilde{y}_{T}\right) & =g\left(S_{k, T} \mid \tilde{y}_{T}\right) \prod_{t=1}^{T} g\left(S_{k, t} \mid S_{k, t+1}, \tilde{y}_{t}\right), \text { for } k=a, b \\
g\left(\tilde{S}_{T} \mid \theta, \tilde{y}_{T}\right) & =g\left(S_{T} \mid \tilde{y}_{T}\right) \prod_{t=1}^{T} g\left(S_{t} \mid S_{t+1}, \tilde{y}_{t}\right) .
\end{aligned}
$$

In order to obtain the two terms on the right-hand side of Equations (29) and (30), the following two steps can be employed:

Step 1: Conditional on the parameters $\theta$, we run the filtering algorithm proposed in Section 2.2, get a draw of $\tilde{\delta}_{T}$, and compute the terms $g\left(\tilde{S}_{k, t} \mid \tilde{y}_{t}\right)$ for $k=a, b$, and $g\left(\tilde{S}_{t} \mid \tilde{y}_{t}\right)$ for $t=1,2, \ldots, T$, save them and take the elements for which $t=T$.

Step 2: The product in the second term of the right-hand side of Equations (29) and (30) can be obtained for $t=T-1, T-2, \ldots, 1$ by following the result:

$$
\begin{aligned}
g\left(S_{t} \mid \tilde{y}_{t}, S_{t+1}\right) & =\frac{g\left(S_{t}, S_{t+1} \mid \tilde{y}_{t}\right)}{g\left(S_{t+1} \mid \tilde{y}_{t}\right)} \\
& \propto g\left(S_{t+1} \mid S_{t}\right) g\left(S_{t} \mid \tilde{y}_{t}\right)
\end{aligned}
$$

where $g\left(S_{t+1} \mid S_{t}\right)$ corresponds to the transition probabilities of $S_{t}$ and $g\left(S_{t} \mid \tilde{y}_{t}\right)$ saved in Step 1.

Then, we compute

$$
\operatorname{Pr}\left[S_{t}=1 \mid S_{t+1}, \tilde{y}_{t}\right]=\frac{g\left(S_{t+1} \mid S_{t}=1\right) g\left(S_{t}=1 \mid \tilde{y}_{t}\right)}{\sum_{j=0}^{1} g\left(S_{t+1} \mid S_{t}=j\right) g\left(S_{t}=j \mid \tilde{y}_{t}\right)},
$$

and generate a random number from $U[0,1]$. If that number is less than or equal to $\operatorname{Pr}\left[S_{t}=\right.$ $\left.{ }_{1} \mid S_{t+1}, \tilde{y}_{t}\right]$, then $S_{t}=1$, otherwise $S_{t}=0$. The same procedure applies for $S_{a, t}$, and $S_{b, t}$.

Draw $p_{a, 00}, p_{a, 11}, p_{b, 00}, p_{b, 11}, p_{00}, p_{11}$.

Conditional on $\tilde{S}_{k, T}$ for $k=a, b$ and $\tilde{S}_{T}$, the transition probabilities are independent from the data set and the model's parameters. Hence, focusing on the case of $\tilde{S}_{T}$, the likelihood function of $p_{00}, p_{11}$ is given by

$$
L\left(p_{00}, p_{11} \mid \tilde{S}_{T}\right)=p_{00}^{n_{00}}\left(1-p_{00}^{n_{01}}\right) p_{11}^{n_{11}}\left(1-p_{11}^{n_{10}}\right)
$$

where $n_{i j}$ refers to the transitions from state $i$ to $j$, accounted for in $\tilde{S}_{T}$. 
Combining the prior distribution with the likelihood, the posterior distribution is given by

$$
p\left(p_{00}, p_{11} \mid \tilde{S}_{T}\right) \propto p_{00}^{u_{00}+n_{00}-1}\left(1-p_{00}\right)^{u_{01}+n_{01}-1} p_{11}^{u_{11}+n_{11}-1}\left(1-p_{11}\right)^{u_{10}+n_{10}-1},
$$

which indicates that draws of the transition probabilities will be taken from

$$
p_{00}\left|\tilde{S}_{T} \sim B e\left(u_{00}+n_{00}, u_{01}+n_{01}\right), p_{11}\right| \tilde{S}_{T} \sim B e\left(u_{11}+n_{11}, u_{10}+n_{10}\right) .
$$

The same procedure applies for the cases of $\tilde{S}_{k, T}$ for $k=a, b$.

Draw $\mu_{0, a}, \mu_{1, a}, \mu_{0, b}, \mu_{1, b}$.

The bivariate Markov-switching model can be expressed compactly as

$$
\begin{aligned}
{\left[\begin{array}{l}
y_{a, t} \\
y_{b, t}
\end{array}\right] } & =\left[\begin{array}{cccc}
1 & S_{a, t} & 0 & 0 \\
0 & 0 & 1 & S_{b, t}
\end{array}\right]\left[\begin{array}{l}
\mu_{a, 0} \\
\mu_{a, 1} \\
\mu_{b, 0} \\
\mu_{b, 1}
\end{array}\right]+\left[\begin{array}{l}
e_{a, t} \\
e_{b, t}
\end{array}\right],\left[\begin{array}{l}
e_{a, t} \\
e_{b, t}
\end{array}\right] \sim N\left(\left[\begin{array}{l}
0 \\
0
\end{array}\right],\left[\begin{array}{cc}
\sigma_{a}^{2} & \sigma_{a b} \\
\sigma_{a b} & \sigma_{b}^{2}
\end{array}\right]\right) \\
y_{t} & =\bar{S}_{t} \mu+\xi_{t}, \quad \xi_{t} \sim N(\mathbf{0}, \Sigma),
\end{aligned}
$$

stacking it as

$$
y=\left[\begin{array}{c}
y_{1} \\
y_{2} \\
\vdots \\
y_{T}
\end{array}\right], \bar{S}=\left[\begin{array}{c}
\bar{S}_{1} \\
\bar{S}_{2} \\
\vdots \\
\bar{S}_{T}
\end{array}\right], \text { and } \xi=\left[\begin{array}{c}
\xi_{1} \\
\xi_{2} \\
\vdots \\
\xi_{T}
\end{array}\right]
$$

The model in Equation (36) remains written as a normal linear regression model with an error covariance matrix of a peculiar form:

$$
y=S \mu+\xi, \quad \xi \sim N(\mathbf{0}, I \otimes \Sigma)
$$

Conditional on the covariance matrix parameters, state variables and the data, by using the corresponding likelihood function, the posterior distribution $p\left(\mu \mid \tilde{S}_{a, T}, \tilde{S}_{b, T}, \tilde{S}_{T}, \tilde{\delta}_{T}, \Sigma^{-1}, \tilde{y}_{T}\right)$ takes the form

$$
\mu \mid \tilde{S}_{a, T}, \tilde{S}_{b, T}, \tilde{S}_{T}, \tilde{\delta}_{T}, \Sigma^{-1}, \tilde{y}_{T} \sim N\left(\bar{\mu}, \bar{V}_{\mu}\right)
$$


where

$$
\begin{aligned}
\bar{V}_{\mu} & =\left(\underline{V}_{\mu}^{-1}+\sum_{t=1}^{T} \bar{S}_{t}^{\prime} \Sigma^{-1} \bar{S}_{t}\right)^{-1} \\
\bar{\mu} & =\bar{V}_{\mu}\left(\underline{V}_{\mu}^{-1} \underline{\mu}+\sum_{t=1}^{T} \bar{S}_{t}^{\prime} \Sigma^{-1} y_{t}\right) .
\end{aligned}
$$

After drawing $\mu=\left(\mu_{a, 0}, \mu_{a, 1}, \mu_{b, 0}, \mu_{b, 1}\right)^{\prime}$ from the above multivariate distribution, if the generated value of $\mu_{a, 1}$ or $\mu_{b, 1}$ is less than or equal to 0 , that draw is discarded; otherwise, it is saved, in order to ensure that $\mu_{a, 1}>0$ and $\mu_{b, 1}>0$.

Draw $\sigma_{a}^{2}, \sigma_{b}^{2}, \sigma_{a b}$.

Conditional on the mean parameters, state variables and the data, by using the corresponding likelihood function, the posterior distribution $p\left(\Sigma^{-1} \mid \tilde{S}_{a, T}, \tilde{S}_{b, T}, \tilde{S}_{T}, \tilde{\delta}_{T}, \mu, \tilde{y}_{T}\right)$ takes the form

$$
\Sigma^{-1} \mid \tilde{S}_{a, T}, \tilde{S}_{b, T}, \tilde{S}_{T}, \tilde{\delta}_{T}, \mu, \tilde{y}_{T} \sim W\left(\bar{S}^{-1}, \bar{v}\right)
$$

where

$$
\begin{aligned}
\bar{v} & =T+\underline{v} \\
\bar{S} & =\underline{S}+\sum_{t=1}^{T}\left(y_{t}-\bar{S}_{t} \mu\right)\left(y_{t}-\bar{S}_{t} \mu\right)^{\prime} .
\end{aligned}
$$

After $\Sigma^{-1}$ is generated, the elements in $\Sigma$ are recovered.

\section{Draw $\alpha$}

In our context of finite samples, small variations in $\alpha$ may end up significantly affecting the dynamics of $\delta_{t}$. To avoid this drawback, instead of simply imposing a given forgetting factor $\alpha$, we use the Bayesian procedure to estimate the other elements of the model and generate draws to simulate the posterior distribution of $\alpha$. We linearize the predicted model probability $\pi_{t+1 \mid t, D}=\delta_{t+1 \mid t}$ in equation (13) to relate it to the updated model probability $\pi_{t \mid t, D}=\delta_{t \mid t}$ in equation (9) with the following linear regression:

$$
\ln \left(\delta_{t+1 \mid t}\right)=\alpha \ln \left(\delta_{t \mid t}\right)+\epsilon_{t}
$$


where $\epsilon_{t}$ is assumed to be normally distributed with variance $\sigma_{\delta}$. Conditional on the variance $\sigma_{\delta}$, using the corresponding likelihood function, the posterior distribution $p\left(\alpha \mid \sigma_{\delta}, \tilde{\delta}_{T}\right)$ takes the form

$$
\alpha \mid \sigma_{\delta}, \tilde{\delta}_{T} \sim N\left(\bar{\alpha}, \bar{\sigma}_{\alpha}\right)
$$

where

$$
\begin{aligned}
\bar{\sigma}_{\alpha} & =\left(\underline{\sigma}_{\alpha}^{-1}+\sigma_{\delta}^{-1} \sum_{t=1}^{T} \ln \left(\delta_{t \mid t}\right)^{2}\right)^{-1} \\
\bar{\alpha} & =\bar{\sigma}_{\alpha}\left(\underline{\sigma}_{\alpha}^{-1} \underline{\alpha}+\sigma_{\delta}^{-1} \sum_{t=1}^{T} \ln \left(\delta_{t \mid t}\right) \ln \left(\delta_{t+1 \mid t}\right)\right) .
\end{aligned}
$$

After obtaining a draw of $\alpha$ from the above posterior distribution, if $0<\alpha<1$, it is saved; otherwise the draw is discarded to ensure the interpretation of a forgetting factor.

\section{Draw $\sigma_{\delta}$}

Conditional on the parameter $\alpha$, and using the corresponding likelihood function, the posterior distribution $p\left(\sigma_{\delta}^{-1} \mid \alpha, \tilde{\delta}_{T}\right)$ takes the form

$$
\sigma_{\delta}^{-1} \mid \alpha, \tilde{\delta}_{T} \sim G\left(\bar{s}^{-1}, \bar{v}\right)
$$

where

$$
\begin{aligned}
& \bar{v}=T+\underline{v} \\
& \bar{s}=\underline{s}+\sum_{t=1}^{T}\left(\ln \left(\delta_{t+1 \mid t}\right)-\alpha \ln \left(\delta_{t \mid t}\right)\right)^{2} .
\end{aligned}
$$

After $\sigma_{\delta}^{-1}$ is generated, the variance $\sigma_{\delta}$ is recovered. 


\section{Appendix B}

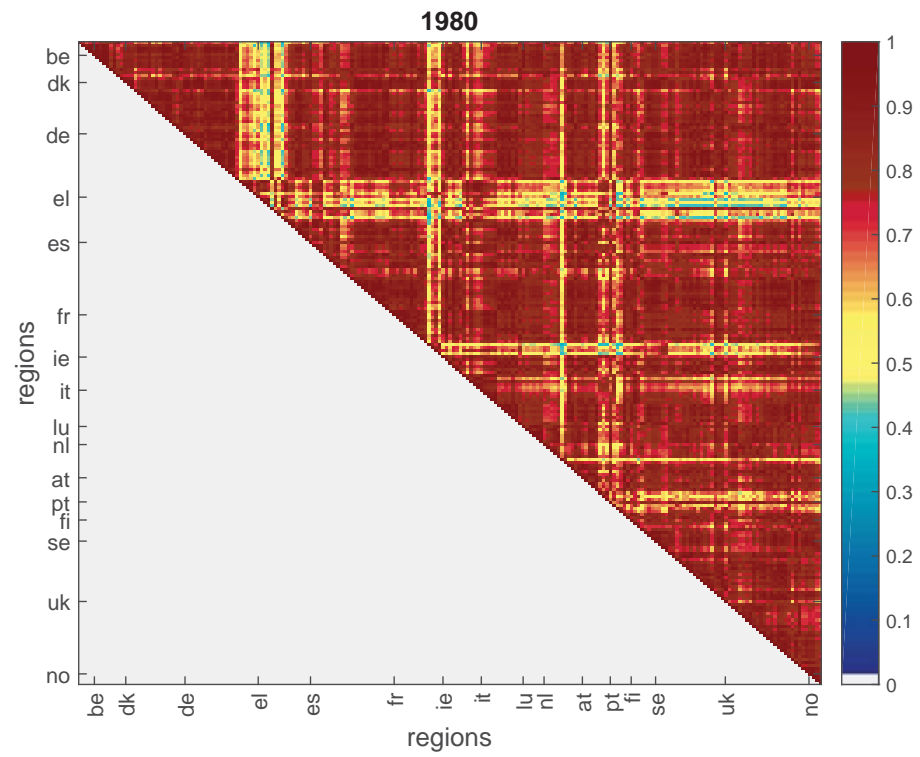

(a) Beginning of the sample: 1980

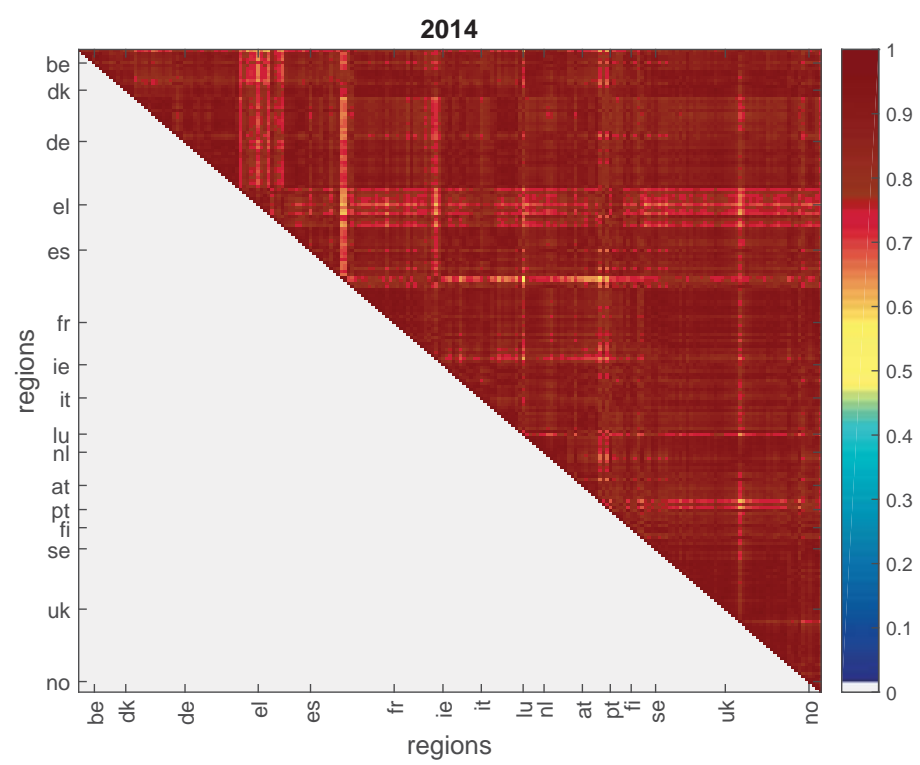

(b) End of the sample: 2014

Figure 11: Map of sectoral similarity across regions

Note. The heatmaps plot the patterns of sectoral composition similarities between European regions at the beginning and at the end the sample. Sectoral composition similarity is computed as in Imbs (2004). 


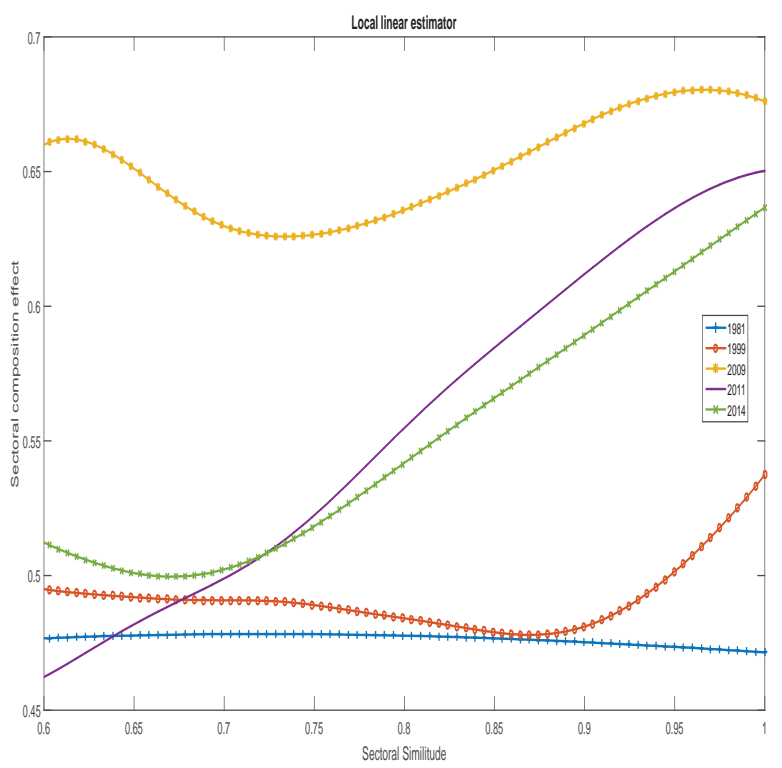

(a) Conditional mean

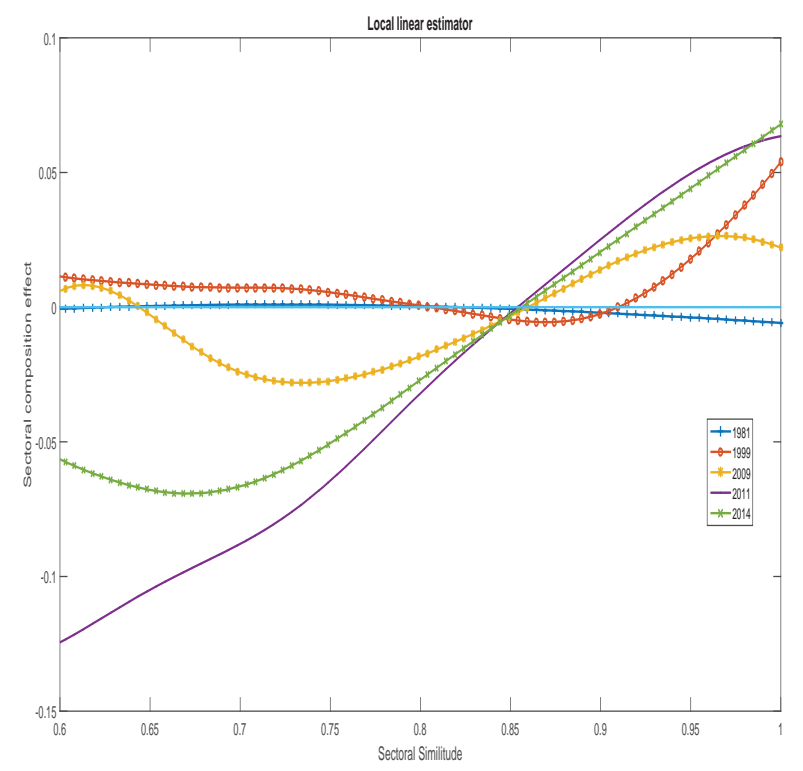

(b) Conditional minus unconditional mean

Figure 12: Expected synchronization conditional on sectoral similarity

Note. Chart (a) shows the conditional expectation of synchronization for selected periods of time, that is, $E_{t}\left(\delta_{t}^{a b} \mid C_{t}^{a b}=c\right)$. Chart (b) shows the conditional minus the unconditional expectation of synchronization for selected periods of time, that is, $\Delta_{t}^{a b}=E_{t}\left(\delta_{t}^{a b} \mid C_{t}^{a b}=c\right)-E_{t}\left(\delta_{t}^{a b}\right)$. 

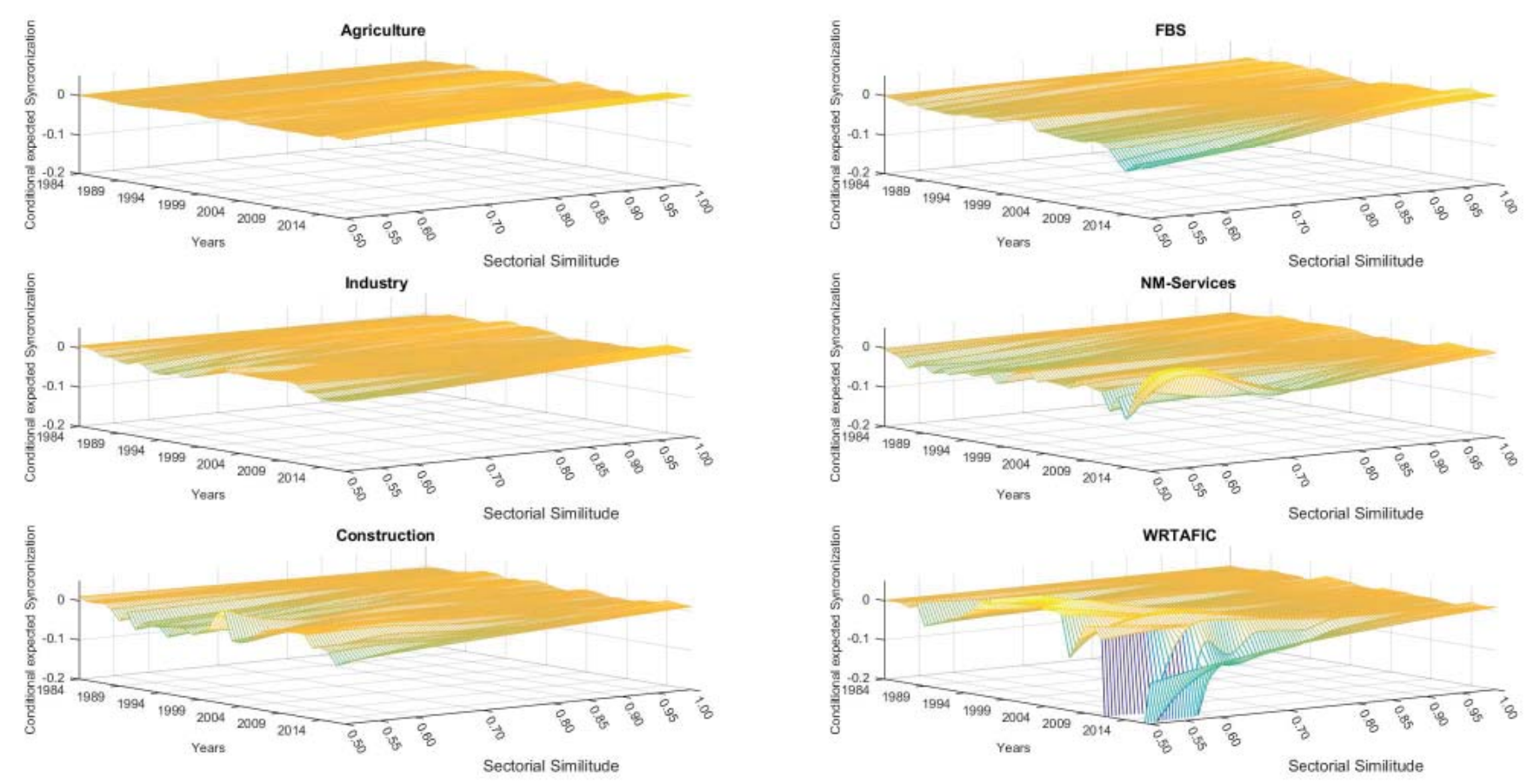

Figure 13: Disaggregated local linear estimators

Note. The charts show the conditional minus the unconditional expectation of synchronization over time for different sectors. 


\title{
BANCO DE ESPAÑA PUBLICATIONS
}

\author{
WORKING PAPERS
}

1530 CRISTINA FERNÁNDEZ and PILAR GARCÍA PEREA: The impact of the euro on euro area GDP per capita.

1531 IRMA ALONSO ÁLVAREZ: Institutional drivers of capital flows.

1532 PAUL EHLING, MICHAEL GALLMEYER, CHRISTIAN HEYERDAHL-LARSEN and PHILIPP ILLEDITSCH: Disagreement about inflation and the yield curve.

1533 GALO NUÑO and BENJAMIN MOLL: Controlling a distribution of heterogeneous agents.

1534 TITO BOERI and JUAN F. JIMENO: The unbearable divergence of unemployment in Europe.

1535 OLYMPIA BOVER: Measuring expectations from household surveys: new results on subjective probabilities of future house prices.

1536 CRISTINA FERNÁNDEZ, AITOR LACUESTA, JOSÉ MANUEL MONTERO and ALBERTO URTASUN: Heterogeneity of markups at the firm level and changes during the great recession: the case of Spain.

1537 MIGUEL SARMIENTO and JORGE E. GALÁN: The influence of risk-taking on bank efficiency: evidence from Colombia.

1538 ISABEL ARGIMÓN, MICHEL DIETSCH and ÁNGEL ESTRADA: Prudential filters, portfolio composition and capital ratios in European banks.

1539 MARIA M. CAMPOS, DOMENICO DEPALO, EVANGELIA PAPAPETROU, JAVIER J. PÉREZ and ROBERTO RAMOS: Understanding the public sector pay gap.

1540 ÓSCAR ARCE, SAMUEL HURTADO and CARLOS THOMAS: Policy spillovers and synergies in a monetary union.

1601 CHRISTIAN CASTRO, ÁNGEL ESTRADA and JORGE MARTÍNEZ: The countercyclical capital buffer in Spain: an analysis of key guiding indicators.

1602 TRINO-MANUEL ÑíGUEZ and JAVIER PEROTE: Multivariate moments expansion density: application of the dynamic equicorrelation model.

1603 ALBERTO FUERTES and JOSÉ MARÍA SERENA: How firms borrow in international bond markets: securities regulation and market segmentation.

1604 ENRIQUE ALBEROLA, IVÁN KATARYNIUK, ÁNGEL MELGUIZO and RENÉ OROZCO: Fiscal policy and the cycle in Latin America: the role of financing conditions and fiscal rules.

1605 ANA LAMO, ENRIQUE MORAL-BENITO and JAVIER J. PÉREZ: Does slack influence public and private labour market interactions?

1606 FRUCTUOSO BORRALLO, IGNACIO HERNANDO and JAVIER VALLÉS: The effects of US unconventional monetary policies in Latin America.

1607 VINCENZO MERELLA and DANIEL SANTABÁRBARA: Do the rich (really) consume higher-quality goods? Evidence from international trade data.

1608 CARMEN BROTO and MATÍAS LAMAS: Measuring market liquidity in US fixed income markets: a new synthetic indicator.

1609 MANUEL GARCÍA-SANTANA, ENRIQUE MORAL-BENITO, JOSEP PIJOAN-MAS and ROBERTO RAMOS: Growing like Spain: 1995-2007.

1610 MIGUEL GARCÍA-POSADA and RAQUEL VEGAS: Las reformas de la Ley Concursal durante la Gran Recesión.

1611 LUNA AZAHARA ROMO GONZÁLEZ: The drivers of European banks' US dollar debt issuance: opportunistic funding in times of crisis?

1612 CELESTINO GIRÓN, MARTA MORANO, ENRIQUE M. QUILIS, DANIEL SANTABÁRBARA and CARLOS TORREGROSA Modelling interest payments for macroeconomic assessment.

1613 ENRIQUE MORAL-BENITO: Growing by learning: firm-level evidence on the size-productivity nexus.

1614 JAIME MARTÍNEZ-MARTÍN: Breaking down world trade elasticities: a panel ECM approach.

1615 ALESSANDRO GALESI and OMAR RACHEDI: Structural transformation, services deepening, and the transmission of monetary policy.

1616 BING XU, ADRIAN VAN RIXTEL and HONGLIN WANG: Do banks extract informational rents through collateral?

1617 MIHÁLY TAMÁS BORSI: Credit contractions and unemployment. 
1618 MIHÁLY TAMÁS BORSI: Fiscal multipliers across the credit cycle.

1619 GABRIELE FIORENTINI, ALESSANDRO GALESI and ENRIQUE SENTANA: A spectral EM algorithm for dynamic factor models.

1620 FRANCISCO MARTÍ and JAVIER J. PÉREZ: Spanish public finances through the financial crisis.

1621 ADRIAN VAN RIXTEL, LUNA ROMO GONZÁLEZ and JING YANG: The determinants of long-term debt issuance by European banks: evidence of two crises.

1622 JAVIER ANDRÉS, ÓSCAR ARCE and CARLOS THOMAS: When fiscal consolidation meets private deleveraging.

1623 CARLOS SANZ: The effect of electoral systems on voter turnout: evidence from a natural experiment.

1624 GALO NUÑO and CARLOS THOMAS: Optimal monetary policy with heterogeneous agents.

1625 MARÍA DOLORES GADEA, ANA GÓMEZ-LOSCOS and ANTONIO MONTAÑÉS: Oil price and economic growth: a long story?

1626 PAUL DE GRAUWE and EDDIE GERBA: Stock market cycles and supply side dynamics: two worlds, one vision?

1627 RICARDO GIMENO and EVA ORTEGA: The evolution of inflation expectations in euro area markets.

1628 SUSANA PÁRRAGA RODRÍGUEZ: The dynamic effect of public expenditure shocks in the United States.

1629 SUSANA PÁRRAGA RODRÍGUEZ: The aggregate effects of government incometransfer shocks - EU evidence.

1630 JUAN S. MORA-SANGUINETTI, MARTA MARTÍNEZ-MATUTE and MIGUEL GARCÍA-POSADA: Credit, crisis and contract enforcement: evidence from the Spanish loan market.

1631 PABLO BURRIEL and ALESSANDRO GALESI: Uncovering the heterogeneous effects of ECB unconventional monetary policies across euro area countries.

1632 MAR DELGADO TÉLLEZ, VÍCTOR D. LLEDÓ and JAVIER J. PÉREZ: On the determinants of fiscal non-compliance: an empirical analysis of Spain's regions.

1633 OMAR RACHEDI: Portfolio rebalancing and asset pricing with heterogeneous inattention.

1634 JUAN DE LUCIO, RAÚL MÍNGUEZ, ASIER MINONDO and FRANCISCO REQUENA: The variation of export prices across and within firms.

1635 JUAN FRANCISCO JIMENO, AITOR LACUESTA, MARTA MARTÍNEZ-MATUTE and ERNESTO VILLANUEVA: Education, labour market experience and cognitive skills: evidence from PIAAC.

1701 JAVIER ANDRÉS, JAVIER J. PÉREZ and JUAN A. ROJAS: Implicit public debt thresholds: an empirical exercise for the case of Spain.

1702 LUIS J. ÁLVAREZ: Business cycle estimation with high-pass and band-pass local polynomial regression.

1703 ENRIQUE MORAL-BENITO, PAUL ALLISON and RICHARD WILLIAMS: Dynamic panel data modelling using maximum likelihood: an alternative to Arellano-Bond.

1704 MIKEL BEDAYO: Creating associations as a substitute for direct bank credit. Evidence from Belgium.

1705 MARÍA DOLORES GADEA-RIVAS, ANA GÓMEZ-LOSCOS and DANILO LEIVA-LEON: The evolution of regional economic interlinkages in Europe.

BANCODEESPAÑA

$$
\text { Eurosistema }
$$

Unidad de Servicios Auxiliares

Alcalá, 48 - 28014 Madrid

E-mail: publicaciones@bde.es www.bde.es 